\title{
Guilty Molecules, Guilty Minds? The Conflicting Roles of the Innate Immune Response to Traumatic Brain Injury
}

\author{
Sarah Claire Hellewell ${ }^{1,2}$ and Maria Cristina Morganti-Kossmann ${ }^{1,3}$ \\ ${ }^{1}$ National Trauma Research Institute, The Alfred Hospital, 89 Commercial Road, Melbourne, VIC 3004, Australia \\ ${ }^{2}$ Department of Medicine, Monash University, Melbourne, VIC 3004, Australia \\ ${ }^{3}$ Department of Surgery, Monash University, Melbourne, VIC 3004, Australia
}

Correspondence should be addressed to Maria Cristina Morganti-Kossmann, cristina.morganti-kossmann@monash.edu

Received 22 December 2011; Accepted 26 March 2012

Academic Editor: Mohamed Lamkanfi

Copyright ( 2012 S. C. Hellewell and M. C. Morganti-Kossmann. This is an open access article distributed under the Creative Commons Attribution License, which permits unrestricted use, distribution, and reproduction in any medium, provided the original work is properly cited.

Traumatic brain injury (TBI) is a complex disease in the most complex organ of the body, whose victims endure lifelong debilitating physical, emotional, and psychosocial consequences. Despite advances in clinical care, there is no effective neuroprotective therapy for TBI, with almost every compound showing promise experimentally having disappointing results in the clinic. The complex and highly interrelated innate immune responses govern both the beneficial and deleterious molecular consequences of TBI and are present as an attractive therapeutic target. This paper discusses the positive, negative, and often conflicting roles of the innate immune response to TBI in both an experimental and clinical settings and highlights recent advances in the search for therapeutic candidates for the treatment of TBI.

\section{Introduction}

Traumatic brain injury (TBI) is a leading cause of death and disability, particularly in young adults who fall victim to motor vehicle accidents, falls, sporting injuries, and increasingly common assaults. Despite advances in prehospital and clinical care, a vast majority of severe TBI survivors will not be able to live independently or return to work [1]. Aside from the enormous personal burden of TBI, a substantial economic cost exists, estimated at $\$ 8.6$ billion dollars each year in Australia alone [2] whilst in the United States this cost exceeds $\$ 55$ billion dollars per year [3].

TBI has been described as the most complex disease in the most complex organ of the body; a sentiment which highlights both the multifactorial nature of brain injury in terms of type and spatial distribution of damage, and the intricacies of the brain's responses to insult. The pathology caused by a TBI can be classified in two broad temporal phases: the primary or initial injury to the head, which cannot be treated or prevented; the secondary injury, which is instigated by the primary injury, results in a complex cascade of pathophysiological and neurochemical events [46 . This ongoing secondary injury process is potentially amenable to intervention and, thus, has been the focus of research in the past two decades, with a view to halting or limiting these factors to avoid the progression of initial injury.

Alas, many compounds showing promise in experimental models have shown largely disappointing results in the clinical setting $[7,8]$, and to date, no effective therapies exist to treat TBI [4]. This failure is likely due to the aforementioned complexities of the brain, and the propensity for use of rodents in preclinical trials of compounds, which overlooks the fundamental differences between human and rodent brains. Another key aspect has been the use of pharmacological agents that target a single factor of the complex interconnected pathways leading to secondary brain damage [9].

The immune system consists of two important components: the "innate" system, which is responsible for immediate, nonspecific action against pathogens or insults, and the "adaptive" system, a response tailored to the specific 
threat or insult at hand [10]. It is increasingly clear that far from being distinct, these systems are highly interrelated, with the innate system shaping and modifying the responses of the adaptive system [11]. Recently, the role of the innate immune system has been under the spotlight, as these early inflammatory responses implicitly designed to minimise the deleterious outcomes of injury have a somewhat paradoxical role in that they are increasingly implicated in the mediation of secondary pathogenic cascades.

The central nervous system (CNS) was traditionally thought to be a site of immune privilege due to the impermeable shield of the blood brain barrier (BBB). However, over the past two decades, it has been well established that under injury and inflammatory conditions, immune cells are able to cross the $\mathrm{BBB}$ and enter the brain parenchyma. The brain is also equipped with its own resident immune cells, the microglia, which undergo marked recruitment, proliferation, and activation in response to virtually any neuropathological insult [12].

This paper aims to provide an insight into the innate immune responses elicited by TBI, and the beneficial or detrimental roles these pivotal responses may exert in the pathogenesis of brain injury. We will also discuss therapies and strategies currently under investigation to minimise the inflammatory response to TBI or modulate it to a more beneficial phenotype.

\section{Pathophysiological Responses to Traumatic Brain Injury}

Initial or primary brain injury results in mechanical damage to the brain as a result of motor vehicle accidents, falls, sporting injuries, and violence [13]. The complex pathology caused by the primary TBI is further complicated by the intrinsic nature of the damage involved: focal or diffuse $[5,14]$. Patients with focal injuries often present with skull fractures and subdural, epidural, or intraparenchymal haematomas [15], with the damage that occurs being largely dependent on the site of impact to the head. In contrast, diffuse brain injury is characterised by widespread damage to the white matter as well as the vasculature caused by acceleration/deceleration forces to the head [16]. Diffuse injury leads to axonal perturbation and impaired axonal transport, with gradual axonal disconnection from the soma [17]. Whilst patients with focal injuries are readily diagnosed using conventional CT scans, diffuse injuries often show no overt pathology and thus can potentially be missed during early imaging-assisted diagnosis $[1,7]$. In addition, focal and diffuse injuries often coexist, particularly in motor vehicle accidents, falls, and assaults [5].

Both focal and diffuse TBIs can cooccur with insults such as hypoxia, hypotension and ischemia, or cerebral hypoperfusion [18-20]. These insults are commonly reported, occurring in approximately one-third of severe TBI patients [21] and are known to exacerbate pathology, with prolonged cognitive deficits and poorer long-term outcome when compared to patients experiencing an isolated TBI [2225]. Animal studies have further elucidated this observation, with posttraumatic insults such as hypoxia and hypotension found to worsen behavioural outcomes and heighten pathology in models of both focal and diffuse injury [26-33].

At the time of the primary TBI, mechanical damage to the brain results in the activation of a multitude of pathways, including (but not limited to) excitotoxicity and oxidative stress, influx of $\mathrm{Ca}^{2+}$ and $\mathrm{Na}^{+}$, and efflux of $\mathrm{K}^{+}$[34-36]. Subsequently, disruption of cell membranes, mitochondrial disturbance leading to energy failure, and a lack of ATP availability hamper reparative mechanisms the brain may attempt $[37,38]$. High intracellular $\mathrm{Ca}^{2+}$ levels also trigger the activation of $\mathrm{Ca}^{2+}$-dependent proteases including calpains, caspases, and phospholipases, resulting in damage to the axonal cytoskeleton [39, 40]. Secondary injury cascades triggered by these primary injurious events include breakdown of the blood brain barrier (BBB) and extravasation of vascular fluid into the parenchyma, ultimately culminating in vasogenic oedema [41-43]. Increased BBB permeability facilitates the infiltration of peripheral immune cells and activation of resident immune cells, which release chemokines and cytokines and thus perpetuate the inflammatory response in the injured brain, with the end result of cellular dysfunction and death [44-46].

\section{The Blood Brain Barrier Allows Transient Passage of Immune Cells into the Injured Brain}

The brain and the CNS have traditionally been considered to be sites of immunological privilege due to the BBB, however during certain inflammatory states, the BBB allows the transient passage of immune cells from the vasculature [47]. The BBB is composed of tight junctions at three sites: endothelial cells in the cerebral capillaries, the arachnoid barrier, and the blood-CSF barrier formed by the choroid plexus $[48,49]$ and is further defined by the associated cellspericytes and astrocytes [49]. Under normal circumstances, the $\mathrm{BBB}$ tightly controls the exchange between plasma and the interstitial fluid, however the dysfunction caused by TBI allows for excess permeability, with disruption of tight junctions and transcytosis allowing passive diffusion. BBB disruption is typically transient, with an immediate period of hyperpermeability, in which immune cells and other products in the plasma may freely cross into the parenchyma $[41,50]$ (Figure 1).

\section{Extravasation of Immune Cells into the Traumatically Injured Brain}

Though peripheral immune cells may enter the CNS via the dysregulated $\mathrm{BBB}$, the $\mathrm{BBB}$ is open for only limited periods of time, and thus cells must also cross the vasculature into the CNS via a process of extravasation. In focal TBI, neutrophils are the first immune cells to enter the injured brain, appearing first on the vascular endothelium within the first 24 hours of injury [51]. The passage of immune cells through the BBB to the parenchyma is mediated by adhesion molecules (Figure 1). These molecules, expressed on both the vascular endothelium and the immune cells themselves, are 


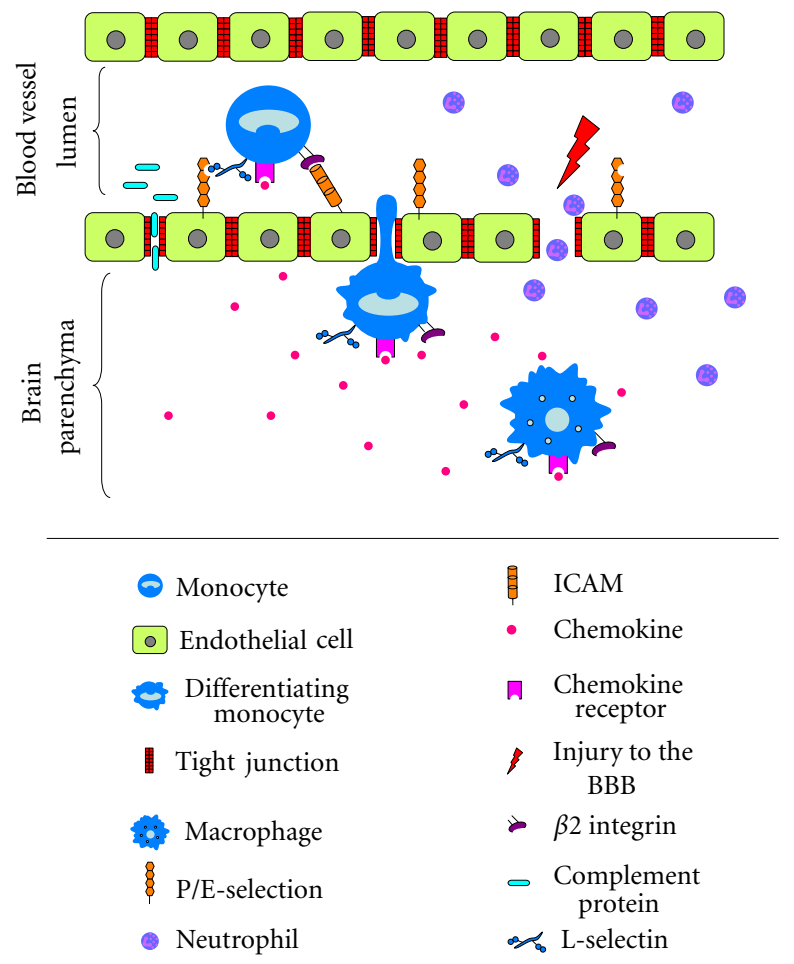

FIGURE 1: Passage of innate immune components through the blood brain barrier (BBB) after TBI. Injury to the brain results in transient opening of the $\mathrm{BBB}$, in which complement proteins and neutrophils are able to directly enter the parenchyma. Peripheral monocytes enter the brain through a process of extravasation, in which several adhesion molecules are upregulated in turn on both the monocyte and endothelial cell to first tether, then provide passage for the cell through the BBB. First, constitutively expressed L-selectin binds to upregulated P/Eselectin on the endothelial cell surface. Once tethered to the endothelium, monocytes are exposed to chemokines that bind to their cognate receptors on the cell, inducing conformational change and upregulation of $\beta 2$ integrins, which bind to ICAMs expressed on endothelial cells. This final interaction between adhesion molecules signals the cell to migrate across the endothelium into the parenchyma, where it begins to differentiate and take on the morphology of an activated macrophage. Under the influence of chemokines, the cell continues the transition to an activated macrophage state migrates to the site of injury. Figure adapted from [58].

important mediators of brain injury as their expression and binding largely regulates the extent of peripheral immune cell entrance to the injured brain [52]. These adhesion molecules are sequentially upregulated to first tether, tightly adhere, and then provide passage for the cell through the vessel wall, beginning with $\mathrm{P}$ - and E-selectin expressed on the endothelium, whilst L-selectin is constitutively expressed on leucocytes [53]. Binding of these molecules tethers the cell to the endothelium, and, once secured, the cell is exposed to chemokines also present on the endothelium, which are highly upregulated in response to injury [54]. The binding of chemokines to their receptors on migratory cells induces conformational change and subsequent activation of the next family of adhesion molecules in the sequence, $\beta 2$ integrins. These proteins, namely, CD11a (LFA-1), CD11b (Mac-1), and CD11c (p50.195) are expressed on the leucocyte cell surface and bind to endothelial cells expressing intercellular adhesion molecules (ICAMs) [52]. ICAMs belong to the immunoglobulin "superfamily" consisting of ICAM-1, ICAM-2, and vascular adhesion molecule (VCAM)-1, as well as ICAM-3, which is expressed on the leucocyte cell surface [53]. It is this binding which gives the final signal for extravasation of the cell through the endothelium into the parenchyma.

In rats, upregulation of E-selectin has been demonstrated on endothelial cells as early as $4 \mathrm{~h}$ after weight-drop injury and remained elevated until $48 \mathrm{~h}$ [55]. ICAM-1 has also been shown to be increased on the endothelium after weightdrop injury $4 \mathrm{~h}$ post-TBI [55]. In diffuse TBI, the number of ICAM-1 positive vessels was also increased by 4 -fold compared to sham at $24 \mathrm{~h}$ [46]. This expression pattern showed late stage amplification, with an 8-fold maximal value observed at 4 days after injury, and only returning to sham levels 1 week after TBI [46].

Children suffering from TBI have also been found to have increased CSF levels of soluble ICAM-1, which correlated with poor outcome [56]. In our adult TBI study, we have reported that patients with large focal contusions had elevated levels of soluble ICAM-1 in their CSF, whilst interestingly, patients with small or absent lesions after TBI showed no such elevations [57]. These differences likely reflect the inconsistencies seen between distinct forms of TBI and may be indicative of the reported contrasts in inflammatory cell infiltrates in animal studies of focal and 
diffuse brain injuries, which will be discussed in more detail in the following sections.

\section{Innate Immune Cells in the Pathogenesis of Brain Injury}

The innate cellular response to TBI involves both infiltrating and resident immune cells, which share many functions in resolving, and at times prolonging the pathological response to injury [11]. Each cell type involved is briefly discussed below.

5.1. Infiltrating Immune Cells. Neutrophils (often referred to as polymorphonuclear cells or leukocytes) are bonemarrow-derived cells which function to phagocytose cellular debris and bacteria [59]. They produce a number of factors designed to be harmful to bacteria and other pathogens, however these substances also have neurotoxic effects on mammalian cells and their release overtly contributes to tissue damage [47]. These molecules include reactive oxygen/nitrogen species (ROS/RNS), matrix metalloproteinases, and proinflammatory cytokines that perpetuate damage in the CNS [37]. After focal TBI, neutrophils are the first immune cell to cross the BBB and enter to sites of injury, though this response is short-lived, with a peak at $24-48 \mathrm{~h}$ after injury and a resolution in neutrophil numbers by 7 days [60-62]. Interestingly, diffuse TBI causes no such infiltration of neutrophils, with only sham-level numbers observed after injury in both immature and adult rats $[46,63]$.

Monocytes/macrophages are also bone marrow derived and contribute to neuroprotection and recovery after CNS injury by phagocytosing cellular debris and preserving healthy tissue. These cells have an important function in antigen presentation to $\mathrm{T}$ cells, and as such are also essential for activation of the adaptive immune response. Acutely after injury, infiltrating macrophages are able to produce growth factors and neurotrophins such as brain-derived neurotrophic factor (BDNF), nerve growth factor (NGF), insulin-like growth factor 1 (IGF1), and anti-inflammatory cytokines such as interleukin (IL)-10 and transforming growth factor- $\beta$ (TGF $\beta$ ) [64]. However, these cells may also be neurotoxic to the injured brain, mediating glutamate release, generating ROS/RNS, and producing chemokines such as CXCL2, CXCL1, CXCL3, and CXCL8 to induce migration of neutrophils [65], and CCL-2 and RANTES to induce migration of monocytes [66]. Activated monocytes/macrophages are also key producers of proinflammatory cytokines such as tumor necrosis factor (TNF), IL$1 \beta$, and IL-6 [67]. As with neutrophils, the recruitment of monocytes is variable between focal and diffuse injury types, with substantially less monocyte recruitment after diffuse injury $[51,68]$.

5.2. The CNS Resident Innate Immune Cells. Microglia are the dynamic surveillance cells of the immune system, constantly exploring their environment for noxious agents and injurious processes $[69,70]$. Microglia play a predominant role in the phagocytosis of cellular debris and respond to extracellular signals by functional transformation from a "resting" to an "activated" phenotype, in which their processes retract, making these cells morphologically and functionally indistinguishable from macrophages [71, 72]. Activated microglia are highly motile and able to rapidly move through the brain to sites of injury [70]. Several neuroinflammatory factors are able to stimulate microglial migration, including the chemokines CCL-2 and fractalkine [73-75] and complement anaphylatoxin C5a [76]. Microglia have long been scrutinized for their role in neuronal damage and particularly in synaptic stripping after TBI [77], however it has now been suggested that, rather than being the perpetrators of neuronal and axonal injury, it is more a case of "guilt by association," since microglia may not be active participants in neuronal damage (for excellent review see [78]). This hypothesis has been corroborated by in vitro experiments of rat neuronal and microglial coculture, in which even when exposed to inflammatory factors, microglia did not cause direct neuronal damage [74].

Astrocytes are the most numerous cell type in the brain and become rapidly activated in response to injury in a process of "reactive astrogliosis," in which cells undergo hypertrophy and proliferation proportional to injury severity $[79,80]$. The role of astrocytes after TBI is controversial, as they are known to produce many proinflammatory cytokines including TNF, IL-1, and IL-6 and are also major producers of chemokines [81]. Astrocytes have also been shown to inhibit axonal spouting in lesioned tissue by formation of a dense fibrous glial scar $[80,82]$. However, this glial scar also restricts tissue damage by forming a protective barrier, confining injury to a defined space and preventing further spread of damage [79, 83]. After TBI, astrocytes decrease the expression of glutamate transporters, with reduced glutamate uptake thus intensifying the excitotoxic response [84]. Conversely, reactive astrocytes upregulate the expression of matrix metalloproteinase (MMP) after TBI, and in particular release of MMP-3, which has been shown to be released from these cells in the vicinity of neurons undergoing synaptogenesis [85], suggesting that astrocytes may play a role in the clearance of damaged tissue in order to make a more permissive environment for neuronal plasticity.

\section{Complement Proteins Are Pivotal in the Pathogenesis of Traumatic Brain Injury}

Best known for its role in the recognition and elimination of pathogens, the complement system has recently emerged as a key innate mediator of the inflammatory response after brain injury. Complement is a complex network of soluble and cell-associated factors [48] and can be activated through three different pathways depending on the stimulus: the classical pathway, the alternative pathway, and the lectin pathway [86]. Within the CNS, complement has been shown to be upregulated both clinically in TBI patients and in various models of experimental TBI [87]. Under normal physiological conditions, complement proteins are detected at very low levels in the brain due to the precise compartmentalization of the vasculature and the parenchyma by the BBB [49], and thus peripheral complement proteins 
are unlikely to enter the brain without disruption of the BBB. After TBI, the disruption of the BBB allows an influx of serum complement proteins into the injured CNS [48, 87] (Figure 1). However, complement proteins can also be produced endogenously in the brain by astrocytes, microglia, and neurons in response to infection or injury [48].

Whilst the role of complement is intrinsically one of elimination and resolution of infection, the infiltration and/or activation of complement proteins after TBI may lead to inflammatory-induced damage by way of $\mathrm{C} 3 \mathrm{~b}$ deposition and subsequent opsonisation and phagocytosis, and C5ainduced recruitment and activation of immune cells from the periphery, with neutrophils being the "early responders" [88]. Overt tissue destruction may also occur with the final formation of the membrane attack complex (MAC), the primary role of which is mechanoporation [86]. Clinically, elevated levels of two crucial components of the alternative pathway, C3 and factor B have been demonstrated in the CSF of severe TBI patients, with concomitant BBB dysfunction in more than $50 \%$ of patients, suggesting that the elevated levels of C3 and factor B, were due to serum leakage across the dysfunctional BBB rather than de novo synthesis [89]. Similarly, C5b-9 (MAC), the cytolytic end product of the complement system has been shown to be increased in the CSF of TBI patients and was accompanied by a loss of integrity of the BBB. Interestingly, several patients in this study experiencing secondary insults such as hypoxemia or hypoperfusion had more pronounced levels of C5b-9 in their CSF [90].

Complement protein synthesis has also been demonstrated in the brain after TBI both experimentally and clinically, with postmortem analysis of human brain tissue revealing the upregulation of $\mathrm{C} 1 \mathrm{q}, \mathrm{C} 3 \mathrm{~b}, \mathrm{C} 3 \mathrm{~d}$, and $\mathrm{C} 5 \mathrm{~b}-9$ in close association with neurons in patients with focal brain contusions [91]. Experimentally, TBI-induced C3 deposition has been demonstrated by immunohistochemistry after lateral fluid percussion TBI [92].

The deleterious role of C5b-9 after TBI has also been demonstrated experimentally in mice null for the C5b9 regulator, CD59. CD59 is able to prevent the formation of C5b-9 and thus acts as an essential inhibitor of complement activation and protector from cell death [93]. Consistent with its role, deletion of CD59 led to worsened neurological outcomes and heightened neuronal cell death, demonstrating the key role of the complement pathway is the pathophysiology of TBI [94]. This detrimental property was corroborated in transgenic mice overexpressing the soluble complement inhibitor Crry (complement receptor, related protein y), which had reduced neurological impairment and improved $\mathrm{BBB}$ dysfunction following TBI compared to wild type controls [95]. Furthermore, the pathogenesis of complement activation after TBI has been demonstrated by dual inhibition of both the classical and alternative pathways by pretreatment of rats with a soluble complement receptor type 1 (sCR1) prior to experimental weight-drop TBI. This dual pharmacological inhibition resulted in a significant decrease in posttraumatic neutrophil infiltration, suggesting that complement activation is an essential mediator of the early neutrophil inflammatory response after TBI [96].
Similarly, experimental TBI using mice deficient for C3 or the downstream $\mathrm{C} 5$, or treatment of wild type mice with the C5a receptor agonist lessened neutrophil extravasation and resulted in smaller lesions [88]. When C3 was injected intracerebrally into C3 deficient mice, the extravasation of neutrophils to the lesion site was amplified, suggesting that that locally produced C3 is important in brain inflammation [88].

\section{Chemokines Mediate Posttraumatic Neuroinflammation and Tissue Damage}

With the ability to dictate directional migration of neutrophils and leukocytes, chemokines are considered essential mediators of posttraumatic neuroinflammation as they control immune cell trafficking from circulation to extravasation [54, 97]. Two main families of chemokines have been described: CXC and CC. The CXC cytokines, including CXCL2, CXCL1, CXCL3, and CXCL8, are predominantly chemoattractant for neutrophils [65], whilst the CC chemokines CCL-2 (MCP-1) and RANTES attract monocytes and lymphocytes [66]. Additionally, a third class of chemokines has been implicated in the pathogenesis of brain injury, the CX3C subfamily, with the only characterised member being fractalkine $\left(\mathrm{CX}_{3} \mathrm{CL} 1\right)$. Fractalkine has the unique ability to attract both neutrophils and monocytes, as well as T cells [98].

Clinically, CXCL8 has been found to be acutely elevated in the CSF and extracellular fluid of patients with severe TBI and correlated with BBB dysfunction and NGF production $[99,100]$. In paediatric TBI, elevation of CXCL8 strongly correlated with mortality [101]. Severe TBI patients also experienced a sustained elevation in levels of CCL-2 for 10 days after injury, though this was highest on days 1 and 2 [97]. Using cerebral microdialysis, several groups have recently demonstrated acutely elevated levels of CCL-3, CCL4 , and RANTES after severe TBI $[100,102]$. A prolonged elevation of fractalkine in the CSF has also been observed in patients after TBI, with a strong correlation to BBB dysfunction and corresponding low fractalkine levels in the serum [103].

Evidence suggests that CXCL1, and particularly CXCL2, are the key mediators of neutrophil migration early after focal brain injury, with both CXCL1 and CXCL2 found to be acutely upregulated within $5 \mathrm{~h}$ of experimental cortical impact injury in both mice and rats $[61,104]$, while after lateral fluid percussion injury CXCL2 expression has been shown to peak at $4 \mathrm{~h}$ in the injured hemisphere [105]. Using mice null for the CXCL2 receptor (CXCR2) in a cortical impact model, our group demonstrated a significant attenuation in the numbers of neutrophils migrating to the site of injury as early as $12 \mathrm{~h}$ after injury, and found that this correlated with reduced amounts of cell death and tissue damage [62].

Ample experimental evidence also exists to demonstrate the presence of monocyte-attracting chemokines acutely after injury, with elevated mRNA for CCL-2, CCL-4 and RANTES all observed after experimental cortical injury [97, 106]. By $4 \mathrm{~h}$, production of CCL-2 and CCL- 4 is significantly 
upregulated both in vivo and in vitro [61, 104, 107], with levels of CCL-2 peaking between 8 and $12 \mathrm{~h}$ after injury $[97,105]$. Elevation of these chemokines after both focal and diffuse TBI is strongly correlated with poor functional outcome [46, 97], with more evidence of this provided using a CCL-2 knockout mouse for cortical injury, in which improved neurological function and reduced lesion volume were attributed to a reduction in macrophage accumulation [97].

This experimental evidence certainly suggests that chemokines play a deleterious role in the pathogenesis of focal brain injury, however their effects in diffuse brain injury are rather different, particularly with respect to CXC (neutrophil-attracting) chemokines. Without the presence of a gross pathological lesion, very low levels of CXCL2 have been observed in diffuse TBI, correlating with absent neutrophil migration into the brain [46]. However, diffuse TBI is associated with abundant accumulation of monocytes/activated microglia in the white matter tracts, colocalising with axonal pathology [28, 108, 109]. This cellular infiltration/activation also correlates with elevated CCL-2 levels acutely after diffuse injury [46]. So, it appears that CC chemokines play a more significant role in diffuse injury, whilst focal injuries involve both $\mathrm{CXC}$ and $\mathrm{CC}$ chemokines. These distinct molecular profiles very much reflect individual modes of cellular infiltration in these injury subsets.

\section{Proinflammatory Cytokines Have Dual Roles in Traumatic Brain Injury}

Proinflammatory cytokines are produced by several types of resident CNS cells such as microglia, astrocytes, and neurons in response to pathological challenge. Cytokines are usually preformed peptides that are activated by cleavage, and swiftly released in response to various stimuli. Once released, cytokines upregulate the expression of cell adhesion molecules and signal the secretion of chemokines in the early postinjury period [47], thus stimulating the infiltration of inflammatory cells to the injured regions. The activation of proinflammatory cytokines in human and rodent TBI has been reported since the early 1990s [99, 101, 102, 110-115]. Their role within the injured brain is, however, one of duality, in that they inherently promote repair, but often bring about additional tissue degeneration by activating a number of cytotoxic pathways leading to cell death [67]. It appears that both the timing of proinflammatory cytokine release and their concentrations are critical to ongoing secondary damage after TBI. The cytokines interleukin IL-1 $\beta$, TNF, IL-6 and granulocyte-colony macrophage stimulating factor (GM-CSF) have been intensely investigated in a multitude of human and experimental paradigms to elucidate their role within the injured brain (see Table 1). Each of these cytokines is discussed in more detail below.

\section{IL-1}

IL-1 is known to induce many signaling pathways stimulating the production of other proinflammatory cytokines and thus is thought to be a key player in initiating the "cytokine cycle" [136]. IL-1 exists in both membrane-bound (IL- $1 \alpha$ ) and secreted (IL-1 $\beta$ ) forms, however it is IL- $1 \beta$ that has earned a reputation as the perpetrator of the acute inflammatory response to TBI. An important distinction is to be made, however, between IL- $1 \beta$ and other cytokines, in that IL- $1 \beta$ itself is not directly toxic when produced; rather it is the propensity to incite other cytokines that lends to its cytotoxic reputation. In noninjured tissue, IL- $1 \beta$ administration alone has been demonstrated to have no ill effects [137], however after TBI IL- $1 \beta$ mRNA is upregulated within minutes, and increased protein levels are detectable within an hour [110, 138-141]. Clinically, acutely elevated levels of IL-1 $\beta$ have been detected after injury by microdialysis [100, 102, 117], in patient CSF $[116,128]$, and directly in perioperative and postmortem brain tissue after TBI at both protein and mRNA levels $[131,142]$. IL- $1 \beta$ levels have also been demonstrated to decrease rapidly; in rat models of focal cortical impact and lateral fluid percussion, IL- $1 \beta$ peaks at $6 \mathrm{~h}$ post-injury and returns to baseline by $72 \mathrm{~h}[143,144]$. This early and transient rise in IL- $1 \beta$ was also consistent with our recent findings in diffuse TBI, with a peak in IL$1 \beta$ levels at $2 \mathrm{~h}$ in the cortex of rats subjected to diffuse TBI [27]. When combined with posttraumatic hypoxia, production of IL- $1 \beta$ was prolonged to $24 \mathrm{~h}$, suggesting that this combinatory insult significantly amplified and sustained this early inflammatory response.

Evidence for the detrimental role of IL- $1 \beta$ is found in experiments in which its expression is modified, with neutralisation of IL- $1 \beta$ in a model of focal TBI in mice resulting in reduced tissue loss and improved visuospatial learning [145]. Furthermore, mice null for the IL-1 receptor (IL-1R1) had decreased VCAM-1 mRNA and a subsequently reduced extravasation of peripheral macrophages after stab wound injury. An overall reduction of inflammation resulted in fewer activated microglia and delayed and depressed expression of cerebral IL-1 and IL-6 [146]. Similarly, blockage of IL- $1 \beta$ signaling by use of an IL- 1 receptor agonist (IL-1ra) has also been shown to delay the production of other proinflammatory cytokines, reduce cell death, and improve neurological recovery after experimental focal TBI and ischaemia [147, 148]. Clinically, endogenous IL-1ra microdialysate levels in have also been correlated with improved outcomes in TBI patients [117]. This largely negative role of IL- $1 \beta$ after injury has also been corroborated by peripheral administration of IL- $1 \beta$ after TBI, leading to larger lesions and impaired behavioural outcomes in rats subjected to fluid percussion injury [118].

\section{TNF}

Along with IL-1 $\beta$, TNF has long been thought of as a cytokine of detriment following injury and still remains a subject of controversy, particularly as both cytokines have many signaling cascades in common and share the same physiologic effects, with the neurotoxic effects of IL- $1 \beta$ synergistically enhanced in the presence of TNF [149]. TNF is produced by microglia and astrocytes and its expression is regulated in an autocrine manner [150]. In TBI patients, 
TABLE 1: Key studies highlighting the dual roles of proinflammatory cytokines after traumatic brain injury.

(a)

\begin{tabular}{|c|c|c|c|}
\hline \multicolumn{4}{|c|}{ IL- $1 \beta$} \\
\hline Finding & Clinical/experimental & Experimental setting & Reference \\
\hline Acutely upregulated after TBI & Clinical & $\begin{array}{c}\text { Cerebral microdialysis; } \\
\text { adult and pediatric patient } \\
\text { CSF }\end{array}$ & {$[100,102,116,117]$} \\
\hline $\begin{array}{l}\text { Peripheral administration after TBI } \\
\text { results in larger lesions and impaired } \\
\text { behavioural outcomes }\end{array}$ & Experimental (rat) & Fluid percussion injury & {$[118]$} \\
\hline $\begin{array}{l}\text { Expression exacerbated and prolonged by } \\
\text { secondary insult }\end{array}$ & Experimental (rat) & $\begin{array}{l}\text { Diffuse axonal injury with } \\
\text { posttraumatic hypoxia }\end{array}$ & {$[27]$} \\
\hline Causes BBB dysfunction in vivo & Experimental (rat; in vitro) & Cerebral endothelial cells & {$[119]$} \\
\hline
\end{tabular}

(b)

\begin{tabular}{|c|c|c|c|}
\hline \multicolumn{4}{|c|}{ TNF } \\
\hline Finding & Clinical/experimental & Study methodology & Reference \\
\hline High levels observed acutely after injury & Clinical & $\begin{array}{l}\text { Cerebral microdialysis, } \\
\text { adult patient CSF }\end{array}$ & $\mathrm{N}[102,120,121]$ \\
\hline Acutely upregulated in rats after focal TBI & Experimental (rat) & $\begin{array}{l}\text { Controlled cortical injury; } \\
\text { lateral fluid percussion }\end{array}$ & {$[115,122]$} \\
\hline $\begin{array}{l}\text { Administration causes BBB dysfunction } \\
\text { and increased recruitment of peripheral } \\
\text { leukocytes }\end{array}$ & $\begin{array}{l}\text { Experimental (rat, } \\
\text { newborn piglet, rat; in } \\
\text { vitro) }\end{array}$ & $\begin{array}{l}\text { Healthy animals/cerebral } \\
\text { endothelial cells }\end{array}$ & $\mathrm{N}[119,123,124]$ \\
\hline $\begin{array}{l}\text { Inhibition of TNF ameliorates BBB } \\
\text { dysfunction }\end{array}$ & Experimental (rat) & Controlled cortical injury & {$[125]$} \\
\hline $\begin{array}{l}\text { Deficiency of TNF/TNF-R causes } \\
\text { exacerbated BBB damage and impairs } \\
\text { long-term recovery }\end{array}$ & Experimental (mouse) & Controlled cortical injury & $\mathrm{N}[126,127]$ \\
\hline $\begin{array}{l}\text { Expression exacerbated and prolonged by } \\
\text { secondary insult }\end{array}$ & Experimental (rat) & $\begin{array}{l}\text { Diffuse axonal injury with } \\
\text { posttraumatic hypoxia }\end{array}$ & {$[27]$} \\
\hline
\end{tabular}

(c)

\begin{tabular}{lccc}
\hline \multicolumn{2}{c}{ IL-6 } & & \\
\hline Finding & Clinical/experimental & Study methodology & Reference \\
\hline $\begin{array}{l}\text { CSF levels correlate with improved } \\
\text { outcome }\end{array}$ & Clinical & Adult and pediatric patient & {$[128,129]$} \\
$\begin{array}{l}\text { Production within 24 h localised to } \\
\text { neurons }\end{array}$ & Experimental (rat) & Diffuse axonal injury & {$[130]$} \\
$\begin{array}{l}\text { IL-6 deficient mice have heightened } \\
\text { neurodegeneration, increased oxidative } \\
\text { stress, poor behavioural recovery }\end{array}$ & Experimental (mouse) & $\begin{array}{c}\text { Controlled cortical injury; } \\
\text { aseptic cerebral injury }\end{array}$ & {$[158-160]$} \\
\hline
\end{tabular}

(d)

\begin{tabular}{lccc}
\hline \multicolumn{4}{c}{ GM-CSF } \\
\hline Finding & Clinical/experimental & Study methodology & Reference \\
\hline $\begin{array}{l}\text { Significantly upregulated in brain tissue } \\
\text { within minutes of TBI }\end{array}$ & Clinical & Postmortem brain tissue & {$[131]$} \\
\hline
\end{tabular}


(d) Continued.

\begin{tabular}{|c|c|c|c|}
\hline \multicolumn{4}{|c|}{ GM-CSF } \\
\hline Finding & Clinical/experimental & Study methodology & Reference \\
\hline $\begin{array}{l}\text { Promotes neuronal stem cell } \\
\text { differentiation in vitro }\end{array}$ & Experimental (rat; in vitro) & Neural stem cell culture & {$[132]$} \\
\hline $\begin{array}{l}\text { Promotes tissue sparing when } \\
\text { administered in conjunction with IL-3 }\end{array}$ & Experimental (rat) & Stab-wound injury & {$[133]$} \\
\hline $\begin{array}{l}\text { Minimises tissue damage and promotes } \\
\text { behavioural recovery }\end{array}$ & Experimental (rat) & Spinal cord contusion & {$[134,135]$} \\
\hline
\end{tabular}

high levels of TNF in the CSF have been observed acutely after injury $[102,120,121]$, although the concentrations of TNF have been detected at considerably lower levels compared to other cytokines such as IL-6, TGF- $\beta$, and IL-8. TNF is also upregulated acutely in various experimental rat models of focal injury $[115,151]$ and has been fingered as a key mediator of the inflammatory response, with exogenous TNF administration in healthy brains causing breakdown down of the $\mathrm{BBB}$ and increasing recruitment of peripheral leukocytes $[119,123,124]$. Consistent with the hypothesised early detrimental role of TNF in the setting of TBI, its inhibition resulted in ameliorated BBB dysfunction [125] and decreased neuronal damage [152]. Whilst most of the evidence to date has documented the deleterious role of TNF in brain injury, this is increasingly becoming an issue of contention, particularly with longer-term studies of TNFdeficient mice, which showed a robust improvement in neurological function initially after TBI, but which then failed to progress in the long term compared to wild type mice [126]. In addition, TNF-deficient mice have also been shown to have exacerbated tissue and BBB damage after TBI [127]. These findings suggest a key detrimental role for TNF in the acute phase, but demonstrate that it may also have a crucial reparative role essential for long-term recovery. The intrigue of TNF action is not only of its temporal benefit or detriment, but also in its differential expression in focal and diffuse brain injuries and speciesspecific expression. Interestingly, the majority of studies examining TNF expression have used rat focal TBI models, and we and other groups have not observed any changes in TNF levels in rats subjected to diffuse TBI [27, 140], despite the fact that, like focal injuries, diffuse TBI evokes a substantial microglial and astrocytic response. However, when rats were subjected to diffuse TBI with posttraumatic hypoxia, our group showed a significant increase in TNF levels at $2 \mathrm{~h}$, which was maintained until $72 \mathrm{~h}$ after injury [27]. In contrast to rat models of focal TBI, in the mouse closed head injury model we have not observed significant upregulation of TNF at any time examined [61, 97], and it is becoming increasingly apparent that there may be a speciesspecific production of TNF in CNS pathologies, in that rats produce more and mice less when subjected to similar levels of brain damage [153].

\section{IL-6}

IL-6 is a true pleiotropic cytokine, with roles in both proand anti-inflammation, and deleterious and beneficial effects after TBI [154-156]. However, it is known most often for its role as an immune stimulator, able to regulate chemokine production, cell adhesion molecule expression, and enhance leukocyte recruitment [157]. Clinical studies have indicated that IL-6 is, for the most part, neuroprotective, with maximal expression observed two days after injury [102, 112, 116] and CSF levels correlating with improved outcome in both children and adults [128, 129]. Previously, we have demonstrated an increase in IL- 6 in the CSF over the first $24 \mathrm{~h}$ after mild experimental diffuse TBI, with production of both IL-6 mRNA and protein localised to neurons [130]. The most telling evidence of the beneficial role for IL-6 has come from studies of IL- 6 gene deficient mice, which have been shown to have poor behavioural recovery, as well as increased oxidative stress, a more compromised immune response, and heightened neurodegeneration [158-160].

\section{GM-CSF}

Granulocyte-macrophage colony-stimulating factor (GMCSF) is a hematopoietic cytokine produced by monocytes, macrophages, and endothelial cells [161], with its receptor expressed on most cell types in the CNS [162]. GM-CSF has been shown to have a positive role in promoting neuronal differentiation of adult stem cells in vitro [132], though as one of the least-examined cytokines after TBI, the role of GM-CSF is still largely to be elucidated. However, GMCSF concentrations have been found to be significantly upregulated in human postmortem brain tissue within minutes of injury [131], indicating that GM-CSF plays an important role in the acute inflammatory response. This role appears to be one of neuroprotection, with a recent study employing stab-wound injury in rats observing that tissue loss was reduced by $40 \%$ when rats were administered a combination of exogenous GM-CSF and IL-3 [133]. Similarly, in models of rat spinal cord injury, rats treated with GM-CSF had reduced numbers of apoptotic cells and significantly improved neurological function [134] as well as reduced glial scar formation, preserved axonal cytoskeleton integrity, and higher numbers of regenerating axons [135]. In addition, rats exposed to focal cerebral ischemia had smaller infarct volumes and altered expression of apoptosis-related genes, with significantly increased levels of the antiapoptotic $\mathrm{Bcl}-2$ and decreased levels of the pro-apoptotic genes Bax and p53 after treatment with GM-CSF [163]. In a mouse model of cerebral ischemia, GM-CSF administration also 
reduced the infarct size and increased the numbers of circulating blood monocytes/macrophages [164]. Taken together, these studies indicate that GM-CSF may play a beneficial role in neuroprotection, however more studies are required to clarify its full potential after TBI.

\section{Toll-Like Receptors Mediate Innate Immune Responses to CNS Trauma}

The toll-like receptors (TLRs) are a family of pattern recognition receptors which mediate innate immune responses to diverse pathogen-associated molecular patterns (PAMPs) [165]. Following injury or neurodegenerative disease without an infectious etiology, the engagement of dangerassociated molecular patterns (DAMPs) by TLRs leads to exacerbated immune activation and enhanced neuropathology $[166,167]$. Like all innate immune responses discussed here, TLR signaling is typically beneficial, yet it has become increasingly clear that following injury signaling through TLRs has particularly pathological consequences, contributing to the activation of microglia and subsequent induction of $\mathrm{NF} \kappa \mathrm{B}$ leading to the transcription of proinflammatory mediators $[168,169]$. Microglia are known to express all recognised TLRs [169], however the expression of TLRs on astrocytes is a contentious topic, with some researchers observing the presence of TLR-2 and TLR- 4 mRNA in astrocyte culture [170], whilst others were unable to identify the expression of any TLR in 99\% pure human astrocytic culture [171].

Many molecules may act as endogenous ligands for TLR signaling, with evidence suggesting that the TLRs involved most in TBI are TLR-2 and TLR-4, and that signaling through these TLRs triggers $\mathrm{NF} \kappa \mathrm{B}$ activation and gene transcription [12]. Whilst research on the role of TLRs after TBI is scant, levels of TLR2 has been noted to be significantly upregulated after mouse bilateral cortical contusion [172], and significant infiltration of TLR-2 positive macrophages/microglia has been observed in the lesioned area and subcortical white matter after weightdrop injury in rats [173]. It appears though that the most compelling evidence of the roles of TLRs in TBI comes from experiments in which they are suppressed or deleted, with TLR-2 knockout mice showing an 18-fold reduction in GFAP mRNA, and 4-fold reduction in CD11b mRNA after stabwound injury when compared to wild type. The authors also found less infiltrating astrocytes in the lesioned area, with those present possessing a less-activated morphology [174], suggesting that activation of TLR-2 was a substantial contributing factor to glial activation. In another study, suppression of TLR-4 using the monosomic alkaloid oxymatrine after focal TBI led to reduced gene expression of $\mathrm{NF} \kappa \mathrm{B}$ and lower concentrations of TNF- $\alpha$, IL- $1 \beta$, and IL- 6 , with fewer apoptotic neurons as a consequence, suggesting a negative role for TLR-4 in neuroinflammation [175]. A doubleknockout of TLR-2 and TLR-4 also resulted in decreased IL$1 \beta$ and MCP- 1 signaling after sciatic nerve damage, as well as significantly decreased macrophage recruitment/microglial activation, however these rats were noted to have poor locomotor recovery, impaired Wallerian degeneration, and inhibited axonal regeneration [176]. Interestingly, a single microinjection of the TLR-2 and TLR-4 ligands at the lesion site resulted in faster clearance of degenerating myelin, and significant and sustained improvement in motor function, indicating that while TLR signaling may be detrimental in terms of the acute neuroinflammatory response, it may in fact be important for long term recovery in terms of myelin clearance and nerve regeneration [176].

\section{Immunotherapies for TBI}

Despite more than 30 years of research, not a single effective therapy has been developed for the treatment of TBI. A multitude of compounds showing promise in animal studies have failed to exhibit beneficial effects in clinical trials, with more than 20 compounds reaching phase II/III trials but showing no long-term benefit [7]. In one of the largest clinical trials for TBI to date, the corticosteroid randomisation after significant head injury (CRASH) trial investigators found that despite encouraging results in animal studies in which corticosteroid treatment was found to be efficacious, in a clinical setting the administration of corticosteroids after TBI was strongly correlated with excess mortality [177].

The lack of success of clinical trials has been attributed to several factors, including superficial examination in animal models with premature translation to the clinic, variations in therapeutic windows in animals and humans and variable dosing schedules, and failure of experimental models to include secondary insults which are commonplace in clinical TBI. Finally, animal models of TBI are by design wellcontrolled and reproducible, whilst clinical TBIs are far more complex and inherently heterogeneous [178, 179]. In order to address these problems, experimental studies are increasingly employing more clinically relevant species with secondary insults, and many compounds are trialed in larger animal models in order to establish efficacy in more clinically relevant brains before moving to clinical trial. Compounds that are currently under investigation for the treatment of TBI fall broadly into two categories: those with multiple targets and modes of action in CNS pathologies, and those with a single target of action. Examples of each with relevance to innate immunity are presented below.

\subsection{Compounds of Multifunctional Modality}

14.1.1. Erythropoietin. Erythropoietin (Epo) is a haematopoietic cytokine produced mainly by the kidney which is rapidly upregulated in response to hypoxia [180]. Epo has been used extensively in the treatment of chronic renal and anaemic patients and has been shown to reduce mortality in trauma patients [181]. In recent years, Epo has been highlighted as a promising neuroprotective candidate due to its current clinical use with few side effects and feasible therapeutic window of $\sim 6$ hours [182]. Epo and its receptor EpoR are rapidly upregulated in the brain after various insult models [183], and its administration after experimental injury was shown to be efficacious in a number of experimental TBI paradigms. Importantly for the treatment of TBI, Epo has numerous targets in the brain, with robust 
benefits including anti-inflammation, with a reduction in immune mediators' levels and subsequent reduction in inflammatory cell infiltrates, diminished cell death, reduction of oedema, rectification of BBB dysfunction, resolution of cerebral vasospasm, as well as enhanced neurogenesis, and angiogenesis and improvement in sensorimotor function [183-187]. Currently, Epo is being investigated in a phase III clinical trial within multiple sites in Australia, with an estimated completion date of 2014.

14.1.2. Minocycline. The tetracycline derivative minocycline has been posited as a neuroprotective candidate in several experimental models of CNS injury due to its potent antiinflammatory actions [61]. After focal TBI in mice, minocycline has been shown to attenuate microglial activation and reduce the expression of IL- $1 \beta[61,188,189]$, as well as acutely reduce the size of focal brain lesions [61, 188, 190] and decrease cerebral oedema [189]. Minocycline may also improve neurological function, however several studies report this effect may be transient, with beneficial outcomes only observed acutely $[61,190]$. Minocycline is currently being investigated in a phase I trial in Detroit, Michigan, with imminent completion.

14.1.3. Progesterone. The hormone progesterone has been shown to have multiple functions in the treatment of brain injury, and is able to exert its effects through steroidal, neuroactive and neurosteroidal mechanisms [191]. Experimentally, progesterone acts as a potent anti-inflammatory agent by dampening the cytokine response and limiting immune cell activation and extravasation [192], as well as decreasing NF $\kappa \mathrm{B}$-mediated inflammatory gene transcription [193]. Progesterone has proved to be particularly effective in the treatment of focal brain injuries, in which it has been demonstrated to reduce neuronal damage, minimise oedema and improve neurological outcomes in a variety of focal contusion models [194-198]. Progesterone can also affect the complement system, with significant reductions in C3 cleaved fragments observed after bilateral frontal contusion in rats [193]. Although limited in number, studies of progesterone's effects on diffuse TBI have also demonstrated benefit with a reported reduction in BBB permeability and subsequent oedema [199] as well as a decreased number of apoptotic cells and the apoptotic precursor caspase 3, and a substantial decline in axonal pathology [200]. Importantly for translation to the clinic, delaying the administration of progesterone for $24 \mathrm{~h}$ still resulted in benefit, with a diminished oedema observed after cortical contusion injury [201]. Due to these benefits in rodent models, progesterone has been applied clinically, with evidence from the ProTECT clinical trial and other pilot studies suggesting that progesterone may reduce mortality and improve neurological outcomes after TBI [202, 203], warranting further investigation in a large multicentre trial. The ProTECT trial has now entered phase III, with an estimated completion date of 2015.

\subsection{Single-Target Compounds}

14.2.1. Complement Inhibition. The complement system presents as an attractive target for immune modulation after TBI due to its prominent role in inflammatory cell extravasation. Several aspects of the complement system are amenable to interventions such as selective antagonists, making them viable candidates for clinical translation. Experimentally, administration of the soluble complement receptor 1 after weight drop injury in the rat significantly attenuates neutrophil infiltration into the injured brain [96]. A similar effect on neutrophil extravasation was also observed after cryoinjury in mice with deletion of either the C3 or C5 gene, or administration of the C5a receptor antagonist, with corresponding reductions in the chemokines CCL5 and CCL2, and smaller lesions as a consequence [88]. Inhibition of the alternative pathway has also shown promising results, with targeted deletion of the factor B gene or delivery of antifactor B neutralising antibody resulting in significantly decreased C5a serum levels and a reduction in cell apoptosis [204, 205]. Although it appears that targeting the complement system in the acute phase may be beneficial, it may also have deleterious consequences for long-term recovery. For example, treatment with the C5a receptor antagonist in rats after spinal cord injury resulted in a significantly less macrophages/microglia in the injury site at 7 days, however these rats also had poor locomotor recovery and reduced myelination, suggesting that while early inhibition of C5a may be beneficial, the longterm outcome of reducing this aspect of inflammation is detrimental [206].

14.2.2. Anticytokine Antibodies. Whilst cytokines appear a natural target for neutralisation as the perpetuators of the inflammatory response, they must be considered in the context of the whole organism, in that the beneficial effects of abolishing such a targeted response may have more broad adverse consequences in recovery. Studies suggest, however, that there may be some benefit to inhibiting the actions of several cytokines, with neutralisation of IL- $1 \beta$ after focal TBI in mice attenuating neutrophil infiltration and microglial activation, minimising the number of ICAM-1 positive cells, and reducing oedema and improving cognitive outcome $[145,207,208]$. Treatment of mice with the IL-1ra has also resulted in benefit in various models and species, with better behavioural scores and attenuation of oxidative stress, as well as smaller lesion volumes $[209,210]$. Importantly for the clinic, IL-1ra is able to penetrate the BBB in concentrations considered to be experimentally therapeutic [211], and even when administration is delayed by $4 \mathrm{~h}$ under experimental conditions, smaller lesion volumes are still observed in an animal model of TBI [210].

Therapeutic inhibition of TNF has also been demonstrated with good result after closed head injury in rats, with a reduction in oedema and recovery of motor function reported $[125,212]$. However, this effect may vary depending on the model of TBI employed, with other researchers finding no benefit when employing neutralising antibodies to TNF in a lateral fluid percussion injury in the rat with respect to oedema, motor, or cognitive outcomes up to one week 
after injury [213]. Results of TNF neutralisation may also vary between species, with no effect observed on behavioural outcomes, lesion volumes or cell death in mice subjected to closed head injury [214].

14.2.3. Antibodies to Cell Adhesion Molecules. Targeting the passage of immune cells through the BBB via inhibition of cell adhesion molecules presents an interesting avenue to dampen the neuroinflammatory response to TBI. Experimentally, administration of antibodies to ICAM-1 resulted in a substantial decrease in neutrophil recruitment [55, 122], however neutrophil accumulation was not completely abolished, thus suggesting a prominent role for other cell adhesion molecules in the absence of ICAM-1 [55]. Neutralisation of ICAM-1 also significantly improved motor performance after lateral fluid percussion injury in the rat, however a significant effect was also seen with IgG injection, indicating that there may be a nonspecific antibody effect [122]. In mice deficient in ICAM-1, however, no beneficial effect was observed with regard to neutrophil accumulation, lesion volume, or motor or cognitive function [215]. In mice double knockout mice for both ICAM-1 and P-selectin, whilst a significant reduction in oedema was observed, no differences to wild type were found with regard to histopathology, motor or cognitive function [216], providing more supporting evidence for a compensatory role of other cell adhesion molecules.

\section{Summary}

The innate immune response plays an intrinsic role in the governance of TBI, with both beneficial and deleterious consequences. This response is largely mediated by resident innate immune cells (microglia and astrocytes), while passage of peripheral immune cells into the brain is facilitated by opening of the BBB, or by upregulation of adhesion molecules and chemokines to aid their movement into the injured tissue. Chemokines such as CXCL2 and CCL-2, and cytokines such as IL- $1 \beta$, TNF, and IL-6 also play essential roles in dictating migration and recruitment of immune cells to sites of injury, with reparative or destructive consequences depending on the timing of their release and their concentrations. Whilst the intention of the innate immune response is to promote repair, restorative efforts are often hampered by the presence of additional inflammatory factors such as complement proteins and increased signaling through microglial TLRs, which results in a disproportionate and self-perpetuating immune response. This dysregulation has become a key target for therapeutic intervention, with both single-target and multifunctional drugs evaluated in efforts to curb the innate immune response. Therapeutic targets are wide ranging, with a focus ranging from adhesion molecules to cytokines in an effort to minimise cell entry, activation and expansion. As yet, no one compound has proven efficacious when applied in multiple models or translated to the clinic, highlighting the need for more rigorous investigation in multiple pathological scenarios prior to clinical application.

\section{Conclusion}

It has become increasingly clear over the last two decades that the innate immune system plays a crucial role in the pathogenesis of TBI. The innate immune system is, by nature, complex and interrelated, with each crucial aspect shaping the structure for the next, and ultimately determining the outcome following TBI. It is this intricate nature, however, which heightens the challenge faced by researchers and clinicians alike in both understanding and combating the secondary consequences of brain trauma. While research into the pathogenesis of TBI is rapidly advancing, many of the complex interactions between compartments of the innate immune response are still unknown. However, with further understanding and more thorough preclinical screening of neuroprotective candidates, the development of an effective therapy for the treatment of TBI could be achieved.

\section{References}

[1] J. A. Myburgh, D. J. Cooper, S. R. Finfer et al., "Epidemiology and 12-month outcomes from traumatic brain injury in Australia and New Zealand," Journal of Trauma, vol. 64, no. 4, pp. 854-862, 2008.

[2] Access Economics PL, The economic cost of spinal cord injury and traumatic brain injury in Australia. Report by Access Economics for the Victorian Neurotrauma Initiative. Canberra: Access Economics, 2009.

[3] D. J. Thurman, C. Alverson, K. A. Dunn, J. Guerrero, and J. E. Sniezek, "Traumatic brain injury in the United States: a public health perspective," Journal of Head Trauma Rehabilitation, vol. 14, no. 6, pp. 602-615, 1999.

[4] A. I. R. Maas, N. Stocchetti, and M. R. Bullock, "Moderate and severe traumatic brain injury in adults," The Lancet Neurology, vol. 7, no. 8, pp. 728-741, 2008.

[5] M. Gaetz, "The neurophysiology of brain injury," Clinical Neurophysiology, vol. 115, no. 1, pp. 4-18, 2004.

[6] B. E. Masel and D. S. DeWitt, "Traumatic brain injury: a disease process, not an event," Journal of Neurotrauma, vol. 27, no. 8, pp. 1529-1540, 2010.

[7] A. I. R. Maas, A. Marmarou, G. D. Murray, G. M. Teasdale, and E. W. Steyerberg, "Prognosis and clinical trial design in traumatic brain injury: the IMPACT study," Journal of Neurotrauma, vol. 24, no. 2, pp. 232-238, 2007.

[8] R. K. Narayan, C. F. Contant, W. M. Coplin et al., "Clinical trials in head injury," Journal of Neurotrauma, vol. 19, no. 5, pp. 503-557, 2002.

[9] R. Vink and M. R. Bullock, "Traumatic brain injury: therapeutic challenges and new directions," Neurotherapeutics, vol. 7, no. 1, pp. 1-2, 2010.

[10] M. Schwartz, G. Moalem, R. Leibowitz-Amit, and I. R. Cohen, "Innate and adaptive immune responses can be beneficial for CNS repair," Trends in Neurosciences, vol. 22, no. 7, pp. 295-299, 1999.

[11] B. Becher, A. Prat, and J. P. Antel, "Brain-immune connection: immuno-regulatory properties of CNS-resident micoGlia," Glia, vol. 29, pp. 293-304, 2000.

[12] D. Soulet and S. Rivest, "Bone-marrow-derived microGlia: 
myth or reality?" Current Opinion in Pharmacology, vol. 8, no. 4 , pp. 508-518, 2008.

[13] J. M. Hardman and A. Manoukian, "Pathology of head trauma," Neuroimaging Clinics of North America, vol. 12, no. 2, pp. 175-187, 2002.

[14] D. H. Smith, D. F. Meaney, and W. H. Shull, "Diffuse axonal injury in head trauma," Journal of Head Trauma Rehabilitation, vol. 18, no. 4, pp. 307-316, 2003.

[15] T. M. J. C. Andriessen, B. Jacobs, and P. E. Vos, "Clinical characteristics and pathophysiological mechanisms of focal and diffuse traumatic brain injury," Journal of Cellular and Molecular Medicine, vol. 14, no. 10, pp. 2381-2392, 2010.

[16] T. A. Gennarelli, L. E. Thibault, J. H. Adams, D. I. Graham, C. J. Thompson, and R. P. Marcincin, "Diffuse axonal injury and traumatic coma in the primate," Annals of Neurology, vol. 12, pp. 564-574, 1982.

[17] O. Farkas and J. T. Povlishock, "Cellular and subcellular change evoked by diffuse traumatic brain injury: a complex web of change extending far beyond focal damage," Progress in Brain Research, vol. 161, pp. 43-59, 2007.

[18] S. L. Bratton, R. M. Chesnut, J. Ghajar et al., "Blood pressure and oxygenation," Journal of Neurotrauma, vol. 24, pp. S7S13, 2007.

[19] R. M. Chesnut, "Secondary brain insults after head injury: clinical perspectives," New Horizons, vol. 3, no. 3, pp. 366375, 1995.

[20] P. Enriquez and R. Bullock, "Molecular and cellular mechanism in the pathophysiology of severe head injury," Current Pharmaceutical Design, vol. 10, no. 18, pp. 2131-2143, 2004.

[21] R. M. Chesnut, L. F. Marshall, M. R. Klauber et al., "The role of secondary brain injury in determining outcome from severe head injury," Journal of Trauma, vol. 34, no. 2, pp. 216 222, 1993.

[22] D. Gentleman and B. Jennett, "Audit of transfer of unconscious head-injured patients to a neurosurgical unit," Lancet, vol. 335, no. 8685, pp. 330-334, 1990.

[23] P. A. Jones, P. J. D. Andrews, S. Midgley et al., "Measuring the burden of secondary insults in head-injured patients during intensive care," Journal of Neurosurgical Anesthesiology, vol. 6, no. 1, pp. 4-14, 1994.

[24] J. J. Chang, T. S. Youn, D. Benson et al., "Physiologic and functional outcome correlates of brain tissue hypoxia in traumatic brain injury," Critical Care Medicine, vol. 37, no. 1, pp. 283-290, 2009.

[25] J. H. Chi, M. M. Knudson, M. J. Vassar et al., "Prehospital hypoxia affects outcome in patients with traumatic brain injury: a prospective multicenter study," Journal of Trauma, vol. 61, no. 5, pp. 1134-1141, 2006.

[26] N. Ishige, L. Pitts, T. Hashimotos, M. Nishimura, and H. Bartkowski, "The effects of hypoxia on traumatic brain injury in rats-part 1: alterations in neurologic function, electroencephalograms, and histopathology," Neurosurgery, vol. 20, pp. 848-853, 1987.

[27] E. B. Yan, S. C. Hellewell, B.-M. Bellander, D. Agyapomaa, and M. C. Morganti-Kossmann, "Post-traumatic hypoxia exacerbates neurological deficit, neuroinflammation and cerebral metabolism in rats with diffuse traumatic brain injury," Journal of Neuroinflammation, vol. 8, article 147, 2011.

[28] S. C. Hellewell, E. B. Yan, D. A. Agyapomaa, N. Bye, and M. C. Morganti-Kossmann, "Post-traumatic hypoxia exacerbates brain tissue damage: analysis of axonal injury and Glial responses," Journal of Neurotrauma, vol. 27, no. 11, pp. 19972010, 2010.
[29] R. S. B. Clark, P. M. Kochanek, C. E. Dixon et al., "Early neuropathologic effects of mild or moderate hypoxemia after controlled cortical impact injury in rats," Journal of Neurotrauma, vol. 14, no. 4, pp. 179-189, 1997.

[30] B. Tavazzi, S. Signoretti, G. Lazzarino et al., "Cerebral oxidative stress and depression of energy metabolism correlate with severity of diffuse brain injury in rats," Neurosurgery, vol. 56, no. 3, pp. 582-588, 2005.

[31] K. Taya, C. R. Marmarou, K. Okuno, R. Prieto, and A. Marmarou, "Effect of secondary insults upon aquaporin-4 water channels following experimental cortical contusion in rats," Journal of Neurotrauma, vol. 27, no. 1, pp. 229-239, 2010.

[32] C. L. Robertson, R. S. B. Clark, C. E. Dixon et al., "No longterm benefit from hypothermia after severe traumatic brain injury with secondary insult in rats," Critical Care Medicine, vol. 28, no. 9, pp. 3218-3223, 2000.

[33] G. Gao, Y. Oda, E. P. Wei, and J. T. Povlishock, "The adverse pial arteriolar and axonal consequences of traumatic brain injury complicated by hypoxia and their therapeutic modulation with hypothermia in rat," Journal of Cerebral Blood Flow and Metabolism, vol. 30, no. 3, pp. 628-637, 2010.

[34] C. L. Floyd, F. A. Gorin, and B. G. Lyeth, "Mechanical strain injury increases intracellular sodium and reverses $\mathrm{Na}^{+} / \mathrm{Ca}^{2+}$ exchange in cortical astrocytes," Glia, vol. 51, no. 1, pp. 3546, 2005.

[35] D. A. Sun, L. S. Deshpande, S. Sombati et al., "Traumatic brain injury causes a long-lasting calcium $(\mathrm{Ca} 2+)$-plateau of elevated intracellular Ca levels and altered $\mathrm{Ca} 2+$ homeostatic mechanisms in hippocampal neurons surviving brain injury," European Journal of Neuroscience, vol. 27, no. 7, pp. 1659-1672, 2008.

[36] Y. Katayama, D. P. Becker, T. Tamura, and D. A. Hovda, "Massive increases in extracellular potassium and the indiscriminate release of glutamate following concussive brain injury," Journal of Neurosurgery, vol. 73, no. 6, pp. 889-900, 1990.

[37] C. Werner and K. Engelhard, "Pathophysiology of traumatic brain injury," British Journal of Anaesthesia, vol. 99, no. 1, pp. 4-9, 2007.

[38] J. Lifshitz, H. Friberg, R. W. Neumar et al., "Structural and functional damage sustained by mitochondria after traumatic brain injury in the rat: evidence for differentially sensitive populations in the cortex and hippocampus," Journal of Cerebral Blood Flow and Metabolism, vol. 23, no. 2, pp. 219-231, 2003.

[39] M. J. McGinn, B. J. Kelley, L. Akinyi et al., "Biochemical, structural, and biomarker evidence for calpain-mediated cytoskeletal change after diffuse brain injury uncomplicated by contusion," Journal of Neuropathology and Experimental Neurology, vol. 68, no. 3, pp. 241-249, 2009.

[40] B. A. Eldadah and A. I. Faden, "Caspase pathways, neuronal apoptosis, and CNS injury," Journal of Neurotrauma, vol. 17, no. 10, pp. 811-829, 2000.

[41] A. W. Unterberg, J. Stover, B. Kress, and K. L. Kiening, "Edema and brain trauma," Neuroscience, vol. 129, no. 4, pp. 1021-1029, 2004.

[42] A. Marmarou, "Pathophysiology of traumatic brain edema: current concepts," Acta Neurochirurgica, Supplementum, no. 86, pp. 7-10, 2003.

[43] A. Beaumont, A. Marmarou, K. Hayasaki et al., "The permissive nature of blood brain barrier (BBB) opening in edema formation following traumatic brain injury," Acta Neurochirurgica, Supplement, vol. 76, pp. 125-129, 2000. 
[44] M. C. Morganti-Kossmann, L. Satgunaseelan, N. Bye, and T. Kossmann, "Modulation of immune response by head injury," Injury, vol. 38, no. 12, pp. 1392-1400, 2007.

[45] S. M. Lucas, N. J. Rothwell, and R. M. Gibson, "The role of inflammation in CNS injury and disease," British Journal of Pharmacology, vol. 147, no. 1, pp. S232-S240, 2006.

[46] M. Rancan, V. I. Otto, V. H. Hans et al., "Upregulation of ICAM-1 and MCP-1 but not of MIP-2 and sensorimotor deficit in response to traumatic axonal injury in rats," Journal of Neuroscience Research, vol. 63, pp. 438-446, 2001.

[47] D. Cederberg and P. Siesjö, "What has inflammation to do with traumatic brain injury?" Child's Nervous System, vol. 26, no. 2, pp. 221-226, 2010.

[48] R. Veerhuis, H. M. Nielsen, and A. J. Tenner, "Complement in the brain," Molecular Immunology, vol. 48, no. 14, pp. 1592$1603,2011$.

[49] N. J. Abbott, A. A. K. Patabendige, D. E. M. Dolman, S. R. Yusof, and D. J. Begley, "Structure and function of the bloodbrain barrier," Neurobiology of Disease, vol. 37, no. 1, pp. 13$25,2010$.

[50] P. Barzó, A. Marmarou, P. Fatouros, F. Corwin, and J. Dunbar, "Magnetic resonance imaging-monitored acute blood-brain barrier changes in experimental traumatic brain injury," Journal of Neurosurgery, vol. 85, no. 6, pp. 1113-1121, 1996.

[58] C. A. Janeway, P. Traves, M. Walport, and M. J. Shlomchik, Immunobiology: The Immune System in Health and Disease, Garland Science, 2005.

[51] H. D. Soares, R. R. Hicks, D. Smith, and T. K. McIntosh, "Inflammatory leukocytic recruitment and diffuse neuronal degeneration are separate pathological processes resulting from traumatic brain injury," Journal of Neuroscience, vol. 15, no. 12, pp. 8223-8233, 1995.

[52] S. J. Lee and E. N. Benveniste, "Adhesion molecule expression and regulation on cells of the central nervous system," Journal of Neuroimmunology, vol. 98, no. 2, pp. 77-88, 1999.

[53] E. G. McKeating and P. J. D. Andrews, "Cytokines and adhesion molecules in acute brain injury," British Journal of Anaesthesia, vol. 80, no. 1, pp. 77-84, 1998.

[54] A. Bajetto, R. Bonavia, S. Barbero, T. Florio, and G. Schettini, "Chemokines and their receptors in the central nervous system," Frontiers in Neuroendocrinology, vol. 22, no. 3, pp. 147-184, 2001.

[55] T. M. Carlos, R. S. B. Clark, D. Franicola-Higgins, J. K. Schiding, and P. M. Kochanek, "Expression of endothelial adhesion molecules and recruitment of neutrophils after traumatic brain injury in rats," Journal of Leukocyte Biology, vol. 61, no. 3, pp. 279-285, 1997.

[56] M. J. Whalen, T. M. Carlos, P. M. Kochanek et al., "Soluble adhesion molecules in CSF are increased in children with severe head injury," Journal of Neurotrauma, vol. 15, no. 10, pp. 777-787, 1998.

[57] U. E. Pleines, J. F. Stover, T. Kossmann, O. Trentz, and M. C. Morganti-Kossmann, "Soluble ICAM-1 in CSF coincides with the extent of cerebral damage in patients with severe traumatic brain injury," Journal of Neurotrauma, vol. 15, no. 6, pp. 399-409, 1998.

[59] M. Scholz, J. Cinatl, M. Schädel-Höpfner, and J. Windolf, "Neutrophils and the blood-brain barrier dysfunction after trauma," Medicinal Research Reviews, vol. 27, no. 3, pp. 401416, 2007.

[60] R. S. B. Clark, J. K. Schiding, S. L. Kaczorowski, D. W. Marion, and P. M. Kochanek, "Neutrophil accumulation after traumatic brain injury in rats: comparison of weight drop and controlled cortical impact models," Journal of Neurotrauma, vol. 11, no. 5, pp. 499-506, 1994.

[61] N. Bye, M. D. Habgood, J. K. Callaway et al., "Transient neuroprotection by minocycline following traumatic brain injury is associated with attenuated microGlial activation but no changes in cell apoptosis or neutrophil infiltration," Experimental Neurology, vol. 204, no. 1, pp. 220-233, 2007.

[62] B. D. Semple, N. Bye, J. M. Ziebell, and M. C. MorgantiKossmann, "Deficiency of the chemokine receptor CXCR2 attenuates neutrophil infiltration and cortical damage following closed head injury," Neurobiology of Disease, vol. 40, no. 2, pp. 394-403, 2010.

[63] P. D. Adelson, M. J. Whalen, P. M. Kochanek, P. Robichaud, and T. M. Carlos, "Blood brain barrier permeability and acute inflammation in two models of traumatic brain injury in the immature rat: a preliminary report," Acta Neurochirurgica, Supplement, vol. 1998, no. 71, pp. 104-106, 1998.

[64] D. Giulian, J. Chen, J. E. Ingeman, J. K. George, and M. Noponen, "The role of mononuclear phagocytes in wound healing after traumatic injury to adult mammalian brain," Journal of Neuroscience, vol. 9, no. 12, pp. 4416-4429, 1989.

[65] Y. Kobayashi, "The role of chemokines in neutrophil biology," Frontiers in Bioscience, vol. 13, no. 7, pp. 2400-2407, 2008.

[66] V. I. Otto, P. F. Stahel, M. Rancan et al., "Regulation of chemokines and chemokine receptors after experimental closed head injury," NeuroReport, vol. 12, no. 9, pp. 20592064, 2001.

[67] P. M. Lenzlinger, M. C. Morganti-Kossmann, H. L. Laurer, and T. K. McIntosh, "The duality of the inflammatory response to traumatic brain injury," Molecular Neurobiology, vol. 24, no. 1-3, pp. 169-181, 2001.

[68] E. Csuka, V. H. J. Hans, E. Ammann, O. Trentz, T. Kossmann, and M. C. Morganti-Kossmann, "Cell activation and inflammatory response following traumatic axonal injury in the rat," NeuroReport, vol. 11, no. 11, pp. 2587-2590, 2000.

[69] D. J. Loane and K. R. Byrnes, "Role of microglia in neurotrauma," Neurotherapeutics, vol. 7, no. 4, pp. 366-377, 2010.

[70] D. Davalos, J. Grutzendler, G. Yang et al., "ATP mediates rapid microGlial response to local brain injury in vivo," Nature Neuroscience, vol. 8, no. 6, pp. 752-758, 2005.

[71] M. B. Graeber and W. J. Streit, "MicroGlia: biology and pathology," Acta Neuropathologica, vol. 119, no. 1, pp. 89$105,2010$.

[72] K. Ohsawa and S. Kohsaka, "Dynamic motility of microGlia: purinergic modulation of microGlial movement in the normal and pathological brain," Glia, vol. 59, pp. 1793-1799, 2011.

[73] M. J. Muessel, R. M. Klein, A. M. Wilson, and N. E. J. Berman, "Ablation of the chemokine monocyte chemoattractant protein-1 delays retrograde neuronal degeneration, attenuates microGlial activation, and alters expression of cell death molecules," Molecular Brain Research, vol. 103, no. 1-2, pp. 12-27, 2002.

[74] A. E. Hinojosa, B. Garcia-Bueno, J. C. Leza, and J. L. M. Madrigal, "CCL2/MCP-1 modulation of microGlial activation and proliferation," Journal of Neuroinflammation, vol. 8, article 77, 2011.

[75] C. Lauro, M. Catalano, F. Trettel et al., "The chemokine CX3CL1 reduces migration and increases adhesion of neurons with mechanisms dependent on the $\beta 1$ integrin subunit," Journal of Immunology, vol. 177, no. 11, pp. 75997606, 2006. 
[76] J. Yao, L. Harvath, D. L. Gilbert, and C. A. Colton, "Chemotaxis by a CNS macrophage, the microGlia," Journal of Neuroscience Research, vol. 27, no. 1, pp. 36-42, 1990.

[77] K. Blinzinger and G. Kreutzberg, "Displacement of synaptic terminals from regenerating motoneurons by microGlial cells," Zeitschrift für Zellforschung und Mikroskopische Anatomie, vol. 85, no. 2, pp. 145-157, 1968.

[78] V. Hugh Perry and V. O'Connor, "The role of microGlia in synaptic stripping and synaptic degeneration:A revised perspective," ASN Neuro, vol. 2, no. 5, Article ID e00047, pp. 281-291, 2010.

[79] D. J. Myer, G. G. Gurkoff, S. M. Lee, D. A. Hovda, and M. V. Sofroniew, "Essential protective roles of reactive astrocytes in traumatic brain injury," Brain, vol. 129, no. 10, pp. 27612772, 2006.

[80] Y. Chen and R. A. Swanson, "Astrocytes and brain injury," Journal of Cerebral Blood Flow and Metabolism, vol. 23, no. 2, pp. 137-149, 2003.

[81] Y. Dong and E. N. Benveniste, "Immune function of astrocytes," Glia, vol. 36, no. 2, pp. 180-190, 2001.

[82] M. D. Laird, J. R. Vender, and K. M. Dhandapani, "Opposing roles for reactive astrocytes following traumatic brain injury," NeuroSignals, vol. 16, no. 2-3, pp. 154-164, 2008.

[83] M. T. Fitch and J. Silver, "Glial cell extracellular matrix: boundaries for axon growth in development and regeneration," Cell and Tissue Research, vol. 290, no. 2, pp. 379-384, 1997.

[84] F. K. H. Van Landeghem, T. Weiss, M. Oehmichen, and A. Von Deimling, "Decreased expression of glutamate transporters in astrocytes after human traumatic brain injury," Journal of Neurotrauma, vol. 23, no. 10, pp. 1518-1528, 2006.

[85] M. C. Falo, H. L. Fillmore, T. M. Reeves, and L. L. Phillips, "Matrix metalloproteinase-3 expression profile differentiates adaptive and maladaptive synaptic plasticity induced by traumatic brain injury," Journal of Neuroscience Research, vol. 84, no. 4, pp. 768-781, 2006.

[86] J. Van Beek, K. Elward, and P. Gasque, "Activation of complement in the central nervous system: roles in neurodegeneration and neuroprotection," Annals of the New York Academy of Sciences, vol. 992, pp. 56-71, 2003.

[87] P. F. Stahel, M. C. Morganti-Kossmann, and T. Kossmann, "The role of the complement system in traumatic brain injury," Brain Research Reviews, vol. 27, no. 3, pp. 243-256, 1998.

[88] D. L. Sewell, B. Nacewicz, F. Liu et al., "Complement C3 and C5 play critical roles in traumatic brain cryoinjury: blocking effects on neutrophil extravasation by C5a receptor antagonist," Journal of Neuroimmunology, vol. 155, no. 1-2, pp. 55-63, 2004.

[89] T. Kossmann, P. F. Stahel, M. C. Morganti-Kossmann, J. L. Jones, and S. R. Barnum, "Elevated levels of the complement components $\mathrm{C} 3$ and factor $\mathrm{B}$ in ventricular cerebrospinal fluid of patients with traumatic brain injury," Journal of Neuroimmunology, vol. 73, no. 1-2, pp. 63-69, 1997.

[90] B. M. Bellander, I. H. Olafsson, P. H. Ghatan et al., "Secondary insults following traumatic brain injury enhance complement activation in the human brain and release of the tissue damage marker S100B," Acta Neurochirurgica, vol. 153, no. 1, pp. 90-100, 2011.

[91] B. M. Bellander, S. K. Singhrao, M. Ohlsson, P. Mattsson, and M. Svensson, "Complement activation in the human brain after traumatic head injury," Journal of Neurotrauma, vol. 18, no. 12, pp. 1295-1311, 2001.

[92] K. L. Keeling, R. R. Hicks, J. Mahesh, B. B. Billings, and
G. J. Kotwal, "Local neutrophil influx following lateral fluid-percussion brain injury in rats is associated with accumulation of complement activation fragments of the third component (C3) of the complement system," Journal of Neuroimmunology, vol. 105, no. 1, pp. 20-30, 2000.

[93] M. C. Morganti-Kossmann, M. Rancan, V. I. Otto, P. F. Stahel, and T. Kossmann, "Role of cerebral inflammation after traumatic brain injury: a revisited concept," Shock, vol. 16, no. 3, pp. 165-177, 2001.

[94] P. F. Stahel, M. A. Flierl, B. P. Morgan et al., "Absence of the complement regulatory molecule CD59a leads to exacerbated neuropathology after traumatic brain injury in mice," Journal of Neuroinflammation, vol. 6, article 2, 2009.

[95] M. Rancan, M. C. Morganti-Kossmann, S. R. Barnum et al., "Central nervous system-targeted complement inhibition mediates neuroprotection after closed head injury in transgenic mice," Journal of Cerebral Blood Flow and Metabolism, vol. 23, no. 9, pp. 1070-1074, 2003.

[96] S. L. Kaczorowski, J. K. Schiding, C. A. Toth, and P. M. Kochanek, "Effect of soluble complement receptor-1 on neutrophil accumulation after traumatic brain injury in rats," Journal of Cerebral Blood Flow and Metabolism, vol. 15, no. 5, pp. 860-864, 1995.

[97] B. D. Semple, N. Bye, M. Rancan, J. M. Ziebell, and M. C. Morganti-Kossmann, "Role of CCL2 (MCP-1) in traumatic brain injury (TBI): evidence from severe TBI patients and CCL2-/- mice," Journal of Cerebral Blood Flow and Metabolism, vol. 30, no. 4, pp. 769-782, 2010.

[98] J. F. Bazan, K. B. Bacon, G. Hardiman et al., "A new class of membrane-bound chemokine with a CX3C motif," Nature, vol. 385, no. 6617, pp. 640-642, 1997.

[99] T. Kossmann, P. F. Stahel, P. M. Lenzlinger et al., "Interleukin8 released into the cerebrospinal fluid after brain injury is associated with blood-brain barrier dysfunction and nerve growth factor production," Journal of Cerebral Blood Flow and Metabolism, vol. 17, no. 3, pp. 280-289, 1997.

[100] P. Mellergård, O. Åneman, F. Sjögren, P. Pettersson, and J. Hillman, "Changes in extracellular concentrations of some cytokines, chemokines, and neurotrophic factors after insertion of intracerebral microdialysis catheters in neurosurgical patients," Neurosurgery, vol. 62, no. 1, pp. 151-158, 2008.

[101] M. J. Whalen, T. M. Carlos, P. M. Kochanek et al., "Interleukin-8 is increased in cerebrospinal fluid of children with severe head injury," Critical Care Medicine, vol. 28, no. 4, pp. 929-934, 2000.

[102] A. Helmy, K. L. Carpenter, D. K. Menon, J. D. Pickard, and P. J. Hutchinson, "The cytokine response to human traumatic brain injury: temporal profiles and evidence for cerebral parenchymal production," Journal of Cerebral Blood Flow \& Metabolism, vol. 31, pp. 658-670, 2011.

[103] M. Rancan, N. Bye, V. I. Otto et al., "The chemokine fractalkine in patients with severe traumatic brain injury and a mouse model of closed head injury," Journal of Cerebral Blood Flow \& Metabolism, vol. 24, pp. 1110-1118, 2004.

[104] A. Vallès, L. Grijpink-Ongering, F. M. de Bree, T. Tuinstra, and E. Ronken, "Differential regulation of the CXCR2 chemokine network in rat brain trauma: implications for neuroimmune interactions and neuronal survival," Neurobiology of Disease, vol. 22, no. 2, pp. 312-322, 2006.

[105] J. K. J. Rhodes, J. Sharkey, and P. J. D. Andrews, "The temporal expression, cellular localization, and inhibition of the chemokines MIP-2 and MCP-1 after traumatic brain injury in the rat," Journal of Neurotrauma, vol. 26, no. 4, pp. 507-525, 2009. 
[106] E. H. S. Hausmann, N. E. J. Berman, Y. Y. Wang, J. B. Meara, G. W. Wood, and R. M. Klein, "Selective chemokine mRNA expression following brain injury," Brain Research, vol. 788, no. 1-2, pp. 49-59, 1998.

[107] A. V. Fahlenkamp, M. Coburn, M. Czaplik et al., "Expression analysis of the early chemokine response $4 \mathrm{~h}$ after in vitro traumatic brain injury," Inflammation Research, vol. 60, no. 4, pp. 379-387, 2011.

[108] B. J. Kelley, J. Lifshitz, and J. T. Povlishock, "Neuroinflammatory responses after experimental diffuse traumatic brain injury," Journal of Neuropathology \& Experimental Neurology, vol. 66, pp. 989-1001, 2007.

[109] M. Oehmichen, I. Theuerkauf, and C. Meißner, "Is traumatic axonal injury (AI) associated with an early microGlial activation? Application of a double-labeling technique for simultaneous detection of microGlia and AI," Acta Neuropathologica, vol. 97, no. 5, pp. 491-494, 1999.

[110] H. Q. Yan, M. A. Banos, P. Herregodts, R. Hooghe, and E. L. Hooghe-Peters, "Expression of interleukin (IL)-1 $\beta$, IL-6 and their respective receptors in the normal rat brain and after injury," European Journal of Immunology, vol. 22, no. 11, pp. 2963-2971, 1992.

[111] T. Kossmann, V. H. Hans, H. G. Imhof et al., "Intrathecal and serum interleukin- 6 and the acute-phase response in patients with severe traumatic brain injuries," Shock, vol. 4, no. 5, pp. 311-317, 1995.

[112] T. Kossmann, V. Hans, H. G. Imhof, O. Trentz, and M. C. Morganti-Kossmann, "Interleukin-6 released in human cerebrospinal fluid following traumatic brain injury may trigger nerve growth factor production in astrocytes," Brain Research, vol. 713, no. 1-2, pp. 143-152, 1996.

[113] V. H. J. Hans, T. Kossmann, H. Joller, V. Otto, and M. C. Morganti-Kossmann, "Interleukin-6 and its soluble receptor in serum and cerebrospinal fluid after cerebral trauma," NeuroReport, vol. 10, no. 2, pp. 409-412, 1999.

[114] M. J. Bell, P. M. Kochanek, L. A. Doughty et al., "Interleukin6 and interleukin-10 in cerebrospinal fluid after severe traumatic brain injury in children," Journal of Neurotrauma, vol. 14, no. 7, pp. 451-457, 1997.

[115] E. Shohami, M. Novikov, R. Bass, A. Yamin, and R. Gallily, "Closed head injury triggers early production of TNF- $\alpha$ and IL-6 by brain tissue," Journal of Cerebral Blood Flow \& Metabolism, vol. 14, pp. 615-619, 1994.

[116] S. D. W. Buttram, S. R. Wisniewski, E. K. Jackson et al., "Multiplex assessment of cytokine and chemokine levels in cerebrospinal fluid following severe pediatric traumatic brain injury: effects of moderate hypothermia," Journal of Neurotrauma, vol. 24, no. 11, pp. 1707-1717, 2007.

[117] P. J. Hutchinson, M. T. O’Connell, N. J. Rothwell et al., "Inflammation in human brain injury: intracerebral concentrations of IL- $1 \alpha$, IL- $1 \beta$, and their endogenous inhibitor IL1ra," Journal of Neurotrauma, vol. 24, no. 10, pp. 1545-1557, 2007.

[118] A. Utagawa, J. S. Truettner, W. D. Dietrich, and H. M. Bramlett, "Systemic inflammation exacerbates behavioural and histopathological consequences of isolated traumatic brain injury in rats," Experimental Neurology, vol. 211, pp. 283-291, 2008.

[119] H. E. deVries, M. C. M. BlomRoosemalen, M. vanOosten et al., "The influence of cytokines on the integrity of the bloodbrain barrier in vitro," Journal of Neuroimmunology, vol. 64, pp. 37-43, 1996.

[120] E. Csuka, M. C. Morganti-Kossmann, P. M. Lenzlinger, H.
Joller, O. Trentz, and T. Kossmann, "IL-10 levels in cerebrospinal fluid and serum of patients with severe traumatic brain injury: relationship to IL-6, TNF- $\alpha$, TGF- $\beta 1$ and bloodbrain barrier function," Journal of Neuroimmunology, vol. 101, no. 2, pp. 211-221, 1999.

[121] J. C. Goodman, M. Van, S. P. Gopinath, and C. S. Robertson, "Pro-inflammatory and pro-apoptotic elements of the neuroinflammatory response are activated in traumatic brain injury," Acta Neurochirurgica, Supplementum, no. 102, pp. 437-439, 2008.

[122] S. M. Knoblach and A. I. Faden, "Administration of either anti-intercellular adhesion molecule-1 or a nonspecific control antibody improves recovery after traumatic brain injury in the rat," Journal of Neurotrauma, vol. 19, no. 9, pp. 10391050, 2002.

[123] K. S. Kim, C. A. Wass, A. S. Cross, and S. M. Opal, "Modulation of blood-brain barrier permeability by tumor necrosis factor and antibody to tumor necrosis factor in the rat," Lymphokine and Cytokine Research, vol. 11, no. 6, pp. 293-298, 1992.

[124] P. Megyeri, C. S. Abraham, P. Temesvari, J. Kovacs, T. Vas, and C. P. Speer, "Recombinant human tumor necrosis factor $\alpha$ constricts pial arterioles and increases blood-brain barrier permeability in newborn piglets," Neuroscience Letters, vol. 148, no. 1-2, pp. 137-140, 1992.

[125] E. Shohami, R. Gallily, R. Mechoulam, R. Bass, and T. Ben-Hur, "Cytokine production in the brain following closed head injury: dexanabinol (HU-211) is a novel TNF$\alpha$ inhibitor and an effective neuroprotectant," Journal of Neuroimmunology, vol. 72, no. 2, pp. 169-177, 1997.

[126] U. Scherbel, R. Raghupathi, M. Nakamura et al., "Differential acute and chronic responses of tumor necrosis factordeficient mice to experimental brain injury," Proceedings of the National Academy of Sciences of the United States of America, vol. 96, no. 15, pp. 8721-8726, 1999.

[127] P. G. Sullivan, A. J. Bruce-Keller, A. G. Rabchevsky et al., "Exacerbation of damage and altered NF- $\kappa$ B activation in mice lacking tumor necrosis factor receptors after traumatic brain injury," Journal of Neuroscience, vol. 19, no. 15, pp. 6248-6256, 1999.

[128] A. Singhal, A. J. Baker, G. M. T. Hare, F. X. Reinders, L. C. Schlichter, and R. J. Moulton, "Association between cerebrospinal fluid interleukin-6 concentrations and outcome after severe human traumatic brain injury," Journal of Neurotrauma, vol. 19, no. 8, pp. 929-937, 2002.

[129] A. Chiaretti, A. Antonelli, A. Mastrangelo et al., "Interleukin6 and nerve growth factor upregulation correlates with improved outcome in children with severe traumatic brain injury," Journal of Neurotrauma, vol. 25, no. 3, pp. 225-234, 2008.

[130] V. H. J. Hans, T. Kossmann, P. M. Lenzlinger et al., "Experimental axonal injury triggers interleukin- 6 mRNA, protein synthesis and release into cerebrospinal fluid," Journal of Cerebral Blood Flow and Metabolism, vol. 19, no. 2, pp. 184194, 1999.

[131] T. Frugier, M. C. Morganti-Kossmann, D. O’Reilly, and C. A. McLean, "In situ detection of inflammatory mediators in post mortem human brain tissue after traumatic injury," Journal of Neurotrauma, vol. 27, no. 3, pp. 497-507, 2010.

[132] C. Krüger, R. Laage, C. Pitzer, W. R. Schäbitz, and A. Schneider, "The hematopoietic factor GM-CSF (Granulocytemacrophage colony-stimulating factor) promotes neuronal differentiation of adult neural stem cells in vitro," $B M C$ Neuroscience, vol. 8, article 88, 2007. 
[133] T. Nishihara, M. Ochi, K. Sugimoto et al., "Subcutaneous injection containing IL-3 and GM-CSF ameliorates stab wound-induced brain injury in rats," Experimental Neurology, vol. 229, no. 2, pp. 507-516, 2011.

[134] Y. Ha, Y. S. Kim, J. M. Cho et al., "Role of granulocytemacrophage colony-stimulating factor in preventing apoptosis and improving functional outcome in experimental spinal cord contusion injury," Journal of neurosurgery. Spine, vol. 2, no. 1, pp. 55-61, 2005.

[135] X. Huang, J. M. Kim, T. H. Kong et al., "GM-CSF inhibits Glial scar formation and shows long-term protective effect after spinal cord injury," Journal of the Neurological Sciences, vol. 277, no. 1-2, pp. 87-97, 2009.

[136] S. M. Gentleman, P. D. Leclercq, L. Moyes et al., "Long-term intracerebral inflammatory response after traumatic brain injury," Forensic Science International, vol. 146, no. 2-3, pp. 97-104, 2004.

[137] N. J. Rothwell, “Cytokines-killers in the brain?” Journal of Physiology, vol. 514, no. 1, pp. 3-17, 1999.

[138] K. Fassbender, S. Schneider, T. Bertsch et al., "Temporal profile of release of interleukin- $1 \beta$ in neurotrauma," Neuroscience Letters, vol. 284, no. 3, pp. 135-138, 2000.

[139] C. G. Gourin and S. R. Shackford, "Production of tumor necrosis factor- $\alpha$ and interleukin- $1 \beta$ by human cerebral microvascular endothelium after percussive trauma," Journal of Trauma, vol. 42, no. 6, pp. 1101-1107, 1997.

[140] K. Kamm, W. Vanderkolk, C. Lawrence, M. Jonker, and A. T. Davis, "The effect of traumatic brain injury upon the concentration and expression of interleukin-1beta and interleukin-10 in the rat," The Journal of trauma., vol. 60, no. 1, pp. 152-157, 2006.

[141] L. Fan, P. R. Young, F. C. Barone et al., "Experimental brain injury induces expression of interleukin-1-beta messengerRNA in the rat brain," Molecular Brain Research, vol. 30, pp. 125-130, 1995.

[142] S. Holmin and B. Höjeberg, "In situ detection of intracerebral cytokine expression after human brain contusion," Neuroscience Letters, vol. 369, no. 2, pp. 108-114, 2004.

[143] J. R. Ciallella, M. D. Ikonomovic, W. R. Paljug et al., "Changes in expression of amyloid precursor protein and interleukin$1 \beta$ after experimental traumatic brain injury in rats," Journal of Neurotrauma, vol. 19, no. 12, pp. 1555-1567, 2002.

[144] S. M. Knoblach and A. I. Faden, "Cortical interleukin- $1 \beta$ elevation after traumatic brain injury in the rat: no effect of two selective antagonists on motor recovery," Neuroscience Letters, vol. 289, no. 1, pp. 5-8, 2000.

[145] F. Clausen, A. Hånell, C. Israelsson et al., "Neutralization of interleukin- $1 \beta$ reduces cerebral edema and tissue loss and improves late cognitive outcome following traumatic brain injury in mice," European Journal of Neuroscience, vol. 34, no. 1, pp. 110-123, 2011.

[146] A. Basu, J. K. Krady, M. O’Malley, S. D. Styren, S. T. DeKosky, and S. W. Levison, "The type 1 interleukin-1 receptor is essential for the efficient activation of microGlia and the induction of multiple proinflammatory mediators in response to brain injury," Journal of Neuroscience, vol. 22, no. 14, pp. 6071-6082, 2002.

[147] R. Tehranian, S. Andell-Jonsson, S. M. Beni et al., "Improved recovery and delayed cytokine induction after closed head injury in mice with central overexpression of the secreted isoform of the interleukin-1 receptor antagonist," Journal of Neurotrauma, vol. 19, no. 8, pp. 939-951, 2002.

[148] N. J. Mulcahy, J. Ross, N. J. Rothwell, and S. A. Loddick, "Delayed administration of interleukin-1 receptor antagonist protects against transient cerebral ischaemia in the rat," British Journal of Pharmacology, vol. 140, no. 3, pp. 471-476, 2003.

[149] C. C. Chao, S. X. Hu, L. Ehrlich, and P. K. Peterson, "Interleukin-1 and tumor necrosis factor- $\alpha$ synergistically mediate neurotoxicity: involvement of nitric oxide and of N-methyl-D-aspartate receptors," Brain, Behavior, and Immunity, vol. 9, no. 4, pp. 355-365, 1995.

[150] J. M. Ziebell and M. C. Morganti-Kossmann, "Involvement of pro- and anti-inflammatory cytokines and chemokines in the pathophysiology of traumatic brain injury," Neurotherapeutics, vol. 7, no. 1, pp. 22-30, 2010.

[151] S. M. Knoblach, L. Fan, and A. I. Faden, "Early neuronal expression of tumor necrosis factor- $\alpha$ after experimental brain injury contributes to neurological impairment," Journal of Neuroimmunology, vol. 95, no. 1-2, pp. 115-125, 1999.

[152] E. Shohami, I. Ginis, and J. M. Hallenbeck, "Dual role of tumor necrosis factor alpha in brain injury," Cytokine and Growth Factor Reviews, vol. 10, no. 2, pp. 119-130, 1999.

[153] M. Schroeter, P. Küry, and S. Jander, "Inflammatory gene expression in focal cortical brain ischemia: differences between rats and mice," Molecular Brain Research, vol. 117, no. 1, pp. 1-7, 2003.

[154] M. C. Morganti-Kossman, P. M. Lenzlinger, V. Hans et al., "Production of cytokines following brain injury: beneficial and deleterious for the damaged tissue," Molecular Psychiatry, vol. 2, no. 2, pp. 133-136, 1997.

[155] M. C. Morganti-Kossmann, M. Rancan, P. F. Stahel, and T. Kossmann, "Inflammatory response in acute traumatic brain injury: a double-edged sword," Current Opinion in Critical Care, vol. 8, no. 2, pp. 101-105, 2002.

[156] R. A. Gadient and U. H. Otten, "Interleukin-6 (IL-6)—a molecule with both beneficial and destructive potentials," Progress in Neurobiology, vol. 52, no. 5, pp. 379-390, 1997.

[157] M. Romano, M. Sironi, C. Toniatti et al., "Role of IL-6 and its soluble receptor in induction of chemokines and leukocyte recruitment," Immunity, vol. 6, no. 3, pp. 315-325, 1997.

[158] M. Penkowa, M. Giralt, J. Carrasco, H. Hadberg, and J. Hidalgo, "Impaired inflammatory response and increased oxidative stress and neurodegeneration after brain injury in interleukin-6-deficient mice," Glia , vol. 32, pp. 271-285, 2000.

[159] E. J. Ley, M. A. Clond, M. B. Singer, D. Shouhed, and A. Salim, "IL6 deficiency affects function after traumatic brain injury," Journal of Surgical Research, vol. 170, pp. 253-256, 2011.

[160] K. R. Swartz, F. Liu, D. Sewell et al., "Interleukin-6 promotes post-traumatic healing in the central nervous system," Brain Research, vol. 896, no. 1-2, pp. 86-95, 2001.

[161] R. Franzen, D. Bouhy, and J. Schoenen, "Nervous system injury: focus on the inflammatory cytokine 'granulocytemacrophage colony stimulating factor"' Neuroscience Letters, vol. 361, no. 1-3, pp. 76-78, 2004.

[162] M. Sawada, Y. Itoh, A. Suzumura, and T. Marunouchi, "Expression of cytokine receptors in cultured neuronal and Glial cells," Neuroscience Letters, vol. 160, no. 2, pp. 131-134, 1993.

[163] T. Kong, J. K. Choi, H. Park et al., "Reduction in programmed cell death and improvement in functional outcome of transient focal cerebral ischemia after administration of granulocyte- macrophage colony-stimulating factor in rats: laboratory investigation," Journal of Neurosurgery, vol. 111, no. 1, pp. 155-163, 2009. 
[164] Y. Sugiyama, Y. Yagita, N. Oyama et al., "Granulocyte colonystimulating factor enhances arteriogenesis and ameliorates cerebral damage in a mouse model of ischemic stroke," Stroke, vol. 42, no. 3, pp. 770-775, 2011.

[165] T. Kawai and S. Akira, “TLR signaling," Seminars in Immunology, vol. 19, pp. 24-32, 2007.

[166] M. L. Hanke and T. Kielian, "Toll-like receptors in health and disease in the brain: mechanisms and therapeutic potential," Clinical Science, vol. 121, pp. 367-387, 2011.

[167] S. Lehnardt, L. Massillon, P. Follett et al., "Activation of innate immunity in the CNS triggers neurodegeneration through a Toll-like receptor 4-dependent pathway," Proceedings of the National Academy of Sciences of the United States of America, vol. 100, no. 14, pp. 8514-8519, 2003.

[168] S. Lehnardt, "Innate immunity and neuroinflammation in the CNS: the role of microGlia in toll-like receptor-mediated neuronal injury," Glia, vol. 58, no. 3, pp. 253-263, 2010.

[169] J. K. Olson and S. D. Miller, "MicroGlia initiate central nervous system innate and adaptive immune responses through multiple TLRs," Journal of Immunology, vol. 173, no. 6, pp. 3916-3924, 2004.

[170] P. A. Carpentier, B. R. Williams, and S. D. Miller, "Distinct roles of protein kinase $\mathrm{R}$ and toll-like receptor 3 in the activation of astrocytes by viral stimuli," Glia, vol. 55, no. 3, pp. 239-252, 2007.

[171] R. N. Aravalli, P. K. Peterson, and J. R. Lokensgard, “Tolllike receptors in defense and damage of the central nervous system," Journal of Neuroimmune Pharmacology, vol. 2, no. 4, pp. 297-312, 2007.

[172] F. Hua, J. Wang, T. Ishrat et al., "Genomic profile of Toll-like receptor pathways in traumatically brain-injured mice: effect of exogenous progesterone," Journal of Neuroinflammation, vol. 8, article 42, 2011.

[173] Z. R. Zhang, Z. Y. Zhang, Y. Z. Wu, and H. J. Schluesener, "Immunolocalization of toll-like receptors 2 and 4 as well as their endogenous ligand, heat shock protein 70 , in rat traumatic brain injury," Neuroimmunomodulation, vol. 19, pp. 10-19, 2012.

[174] C. Park, I. H. Cho, D. Kim et al., "Toll-like receptor 2 contributes to Glial cell activation and heme oxygenase-1 expression in traumatic brain injury," Neuroscience Letters, vol. 431, no. 2, pp. 123-128, 2008.

[175] X. Q. Dong, W. H. Yu, Y. Y. Hu, Z. Y. Zhang, and M. Huang, "Oxymatrine reduces neuronal cell apoptosis by inhibiting Toll-like receptor 4/nuclear factor kappa-Bdependent inflammatory responses in traumatic rat brain injury," Inflammation Research, vol. 60, no. 6, pp. 533-539, 2011.

[176] A. Boivin, I. Pineau, B. Barrette et al., "Toll-like receptor signaling is critical for Wallerian degeneration and functional recovery after peripheral nerve injury," Journal of Neuroscience, vol. 27, no. 46, pp. 12565-12576, 2007.

[177] I. Muzha, N. Filipi, R. Lede et al., "Effect of intravenous corticosteroids on death within 14 days in 10008 adults with clinically significant head injury (MRC CRASH trial): randomised placebo-controlled trial," Lancet, vol. 364, pp. 1321-1328, 2004.

[178] R. Vink and A. J. Nimmo, "Multifunctional Drugs for Head Injury," Neurotherapeutics, vol. 6, no. 1, pp. 28-42, 2009.

[179] S. Margulies and R. Hicks, "Combination therapies for traumatic brain injury: prospective considerations," Journal of Neurotrauma, vol. 26, no. 6, pp. 925-939, 2009.

[180] K. Maiese, Z. C. Zhao, J. Hou, and C. S. Yan, "Erythropoietin and oxidative stress," Current Neurovascular Research, vol. 5, no. 2, pp. 125-142, 2008

[181] H. L. Corwin, A. Gettinger, T. C. Fabian et al., "Efficacy and safety of epoetin alfa in critically ill patients," New England Journal of Medicine, vol. 357, no. 10, pp. 965-976, 2007.

[182] M. Brines and A. Cerami, "Erythropoietin-mediated tissue protection: reducing collateral damage from the primary injury response," Journal of Internal Medicine, vol. 264, no. 5, pp. 405-432, 2008.

[183] M. L. Brines, P. Ghezzi, S. Keenan et al., "Erythropoietin crosses the blood-brain barrier to protect against experimental brain injury," Proceedings of the National Academy of Sciences of the United States of America, vol. 97, no. 19, pp. 10526-10531, 2000.

[184] G. Grasso, A. Sfacteria, F. Meli, V. Fodale, M. Buemi, and D. G. Iacopino, "Neuroprotection by erythropoietin administration after experimental traumatic brain injury," Brain Research, vol. 1182, no. 1, pp. 99-105, 2007.

[185] O. Verdonck, H. Lahrench, G. Francony et al., "Erythropoietin protects from post-traumatic edema in the rat brain," Journal of Cerebral Blood Flow \& Metabolism, vol. 27, pp. 1369-1376, 2007.

[186] J. B. Springborg, C. Moller, P. Gideon, O. S. Jorgensen, M. Juhler, and N. V. Olsen, "Erythropoietin in patients with aneurysmal subarachnoid haemorrhage: a double blind randomised clinical trial," Acta Neurochirurgica, vol. 149, pp. 1089-1100, 2007.

[187] Z. Z. Chong, J. Q. Kang, and K. Maiese, "Erythropoietin fosters both intrinsic and extrinsic neuronal protection through modulation of microGlia, Akt1, Bad, and caspasemediated pathways," British Journal of Pharmacology, vol. 138, no. 6, pp. 1107-1118, 2003.

[188] S. Homsi, T. Piaggio, N. Croci et al., "Blockade of acute microGlial activation by minocycline promotes neuroprotection and reduces locomotor hyperactivity after closed head injury in mice: a twelve-week follow-up study," Journal of Neurotrauma, vol. 27, no. 5, pp. 911-921, 2010.

[189] S. Homsi, F. Federico, N. Croci et al., "Minocycline effects on cerebral edema: relations with inflammatory and oxidative stress markers following traumatic brain injury in mice," Brain Research, vol. 1291, pp. 122-132, 2009.

[190] R. O. Sanchez Mejia, V. O. Ona, M. Li, and R. M. Friedlander, "Minocycline reduces traumatic brain injury-mediated caspase- 1 activation, tissue damage, and neurological dysfunction," Neurosurgery, vol. 48, no. 6, pp. 1393-1401, 2001.

[191] M. Junpeng, S. Huang, and S. Qin, "Progesterone for acute traumatic brain injury," Cochrane Database of Systematic Reviews, vol. 1, Article ID CD008409, 2011.

[192] T. C. Chao, P. J. Vanalten, J. A. Greager, and R. J. Walter, "Steroid sex-hormones regulate the release of tumornecrosis-factor by macrophages," Cellular Immunology, vol. 160, pp. 43-49, 1995.

[193] E. H. Pettus, D. W. Wright, D. G. Stein, and S. W. Hoffman, "Progesterone treatment inhibits the inflammatory agents that accompany traumatic brain injury," Brain Research, vol. 1049, no. 1, pp. 112-119, 2005.

[194] C. K. Barha, T. Ishrat, J. R. Epp, L. A. M. Galea, and D. G. Stein, "Progesterone treatment normalizes the levels of cell proliferation and cell death in the dentate gyrus of the hippocampus after traumatic brain injury," Experimental Neurology, vol. 231, no. 1, pp. 72-81, 2011.

[195] R. L. Roof, R. Duvdevani, L. Braswell, and D. G. Stein, "Progesterone facilitates cognitive recovery an reduces secondary neuronal loss caused by cortical contusion injury in male rats," Experimental Neurology, vol. 129, no. 1, pp. 64-69, 
1994.

[196] M. Djebaili, S. W. Hoffman, and D. G. Stein, "Allopregnanolone and progesterone decrease cell death and cognitive deficits after a contusion of the rat pre-frontal cortex," Neuroscience, vol. 123, no. 2, pp. 349-359, 2004.

[197] M. Djebaili, Q. Guo, E. H. Pettus, S. W. Hoffman, and D. G. Stein, "The neurosteroids progesterone and allopregnanolone reduce cell death, gliosis, and functional deficits after traumatic brain injury in rats," Journal of Neurotrauma, vol. 22, no. 1, pp. 106-118, 2005.

[198] J. He, S. W. Hoffman, and D. G. Stein, "Allopregnanolone, a progesterone metabolite, enhances behavioral recovery and decreases neuronal loss after traumatic brain injury," Restorative Neurology and Neuroscience, vol. 22, no. 1, pp. 1931, 2004.

[199] C. A. O'Connor, I. Cernak, and R. Vink, "Both estrogen and progesterone attenuate edema formation following diffuse traumatic brain injury in rats," Brain Research, vol. 1062, no. 1-2, pp. 171-174, 2005.

[200] C. A. O'Connor, I. Cernak, F. Johnson, and R. Vink, "Effects of progesterone on neurologic and morphologic outcome following diffuse traumatic brain injury in rats," Experimental Neurology, vol. 205, no. 1, pp. 145-153, 2007.

[201] R. L. Roof, R. Duvdevani, J. W. Heyburn, and D. G. Stein, "Progesterone rapidly decreases brain edema: treatment delayed up to 24 hours is still effective," Experimental Neurology, vol. 138, no. 2, pp. 246-251, 1996.

[202] D. W. Wright, A. L. Kellermann, V. S. Hertzberg et al., "ProTECT: a randomized clinical trial of progesterone for acute traumatic brain injury," Annals of Emergency Medicine, vol. 49, no. 4, pp. 391-402, 2007.

[203] G. M. Xiao, J. Wei, W. Q. Yan, W. M. Wang, and Z. H. Lu, "Improved outcomes from the administration of progesterone for patients with acute severe traumatic brain injury: a randomized controlled trial," Critical Care, vol. 12, no. 2, article R61, 2008.

[204] I. Leinhase, V. M. Michael, J. M. Thurman et al., "Reduced neuronal cell death after experimental brain injury in mice lacking a functional alternative pathway of complement activation," BMC Neuroscience, vol. 7, article 55, 2006.

[205] I. Leinhase, M. Rozanski, D. Harhausen et al., "Inhibition of the alternative complement activation pathway in traumatic brain injury by a monoclonal anti-factor B antibody: a randomized placebo-controlled study in mice," Journal of Neuroinflammation, vol. 4, article 13, 2007.

[206] K. D. Beck, H. X. Nguyen, M. D. Galvan, D. L. Salazar, T. M. Woodruff, and A. J. Anderson, "Quantitative analysis of cellular inflammation after traumatic spinal cord injury: evidence for a multiphasic inflammatory response in the acute to chronic environment," Brain, vol. 133, no. 2, pp. 433-447, 2010.

[207] F. Clausen, A. Hanell, M. Bjork et al., "Neutralization of interleukin-1 beta modifies the inflammatory response and improves histological and cognitive outcome following traumatic brain injury in mice," European Journal of Neuroscience, vol. 30, pp. 385-396, 2009.

[208] M. Shibayama, H. Kuchiwaki, S. Inao, K. Yoshida, and M. Ito, "Intercellular adhesion molecule-1 expression on Glia following brain injury: participation of interleukin-1 $\beta$," Journal of Neurotrauma, vol. 13, no. 12, pp. 801-808, 1996.

[209] N. R. Jones, M. J. W. Prior, E. Burden-Teh, C. A. Marsden, P. G. Morris, and S. Murphy, "Antagonism of the interleukin1 receptor following traumatic brain injury in the mouse reduces the number of nitric oxide synthase-2-positive cells and improves anatomical and functional outcomes," European Journal of Neuroscience, vol. 22, pp. 72-78, 2005.

[210] S. Toulmond and N. J. Rothwell, "Interleukin-1 receptor antagonist inhibits neuronal damage caused by fluid percussion injury in the rat," Brain Research, vol. 671, no. 2, pp. 261266, 1995.

[211] S. R. Clark, C. J. McMahon, I. Gueorguieva et al., "Interleukin-1 receptor antagonist penetrates human brain at experimentally therapeutic concentrations," Journal of Cerebral Blood Flow \& Metabolism, vol. 28, pp. 387-394, 2008.

[212] E. Shohami, R. Bass, D. Wallach, A. Yamin, and R. Gallily, "Inhibition of tumor necrosis factor alpha (TNF $\alpha$ ) activity in rat brain is associated with cerebroprotection after closed head injury," Journal of Cerebral Blood Flow \& Metabolism, vol. 16, pp. 378-384, 1996.

[213] N. Marklund, C. Keck, R. Hoover et al., "Administration of monoclonal antibodies neutralizing the inflammatory mediators tumor necrosis factor alpha and interleukin 6 does not attenuate acute behavioral deficits following experimental traumatic brain injury in the rat," Restorative Neurology and Neuroscience, vol. 23, no. 1, pp. 31-42, 2005.

[214] J. M. Ziebell, N. Bye, B. D. Semple, T. Kossmann, and M. C. Morganti-Kossmann, "Attunuated neurological deficit, cell death and lesion volume in Fas-mutant mice is associated with altered neuroinflammation following traumatic brain injury," Brain Research, vol. 1414, pp. 94-105, 2011.

[215] M. J. Whalen, T. M. Carlos, C. E. Dixon et al., "Effect of traumatic brain injury in mice deficient in intercellular adhesion molecule-1: assessment of histopathologic and functional outcome," Journal of Neurotrauma, vol. 16, no. 4, pp. 299-309, 1999.

[216] M. J. Whalen, T. M. Carlos, C. E. Dixon et al., "Reduced brain edema after traumatic brain injury in mice deficient in P-selectin and intercellular adhesion molecule-1," Journal of Leukocyte Biology, vol. 67, no. 2, pp. 160-168, 2000. 


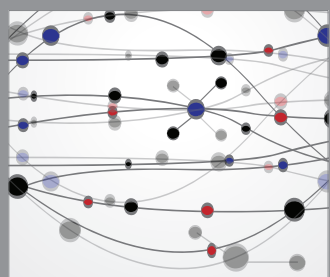

The Scientific World Journal
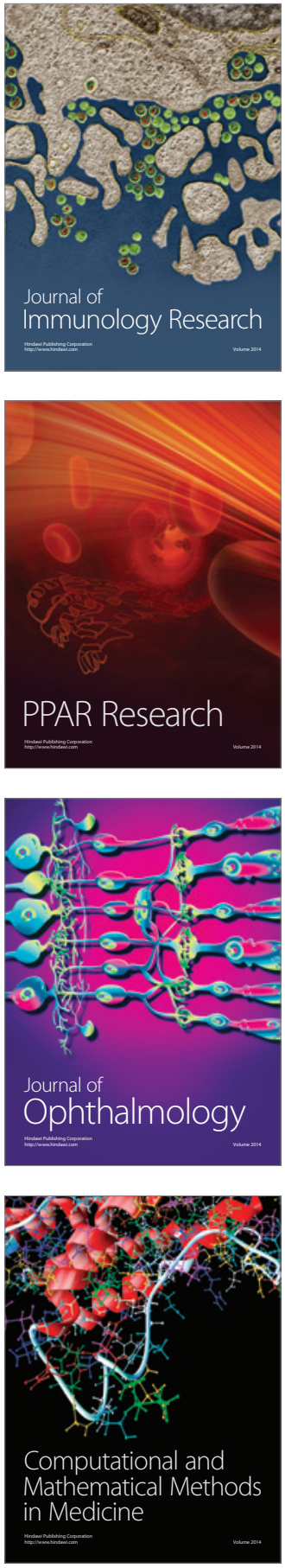

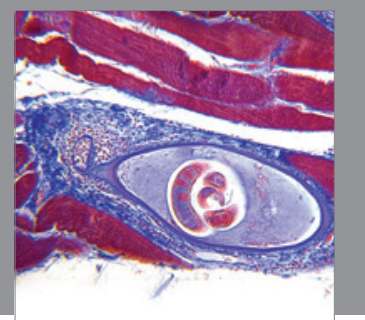

Gastroenterology

Research and Practice
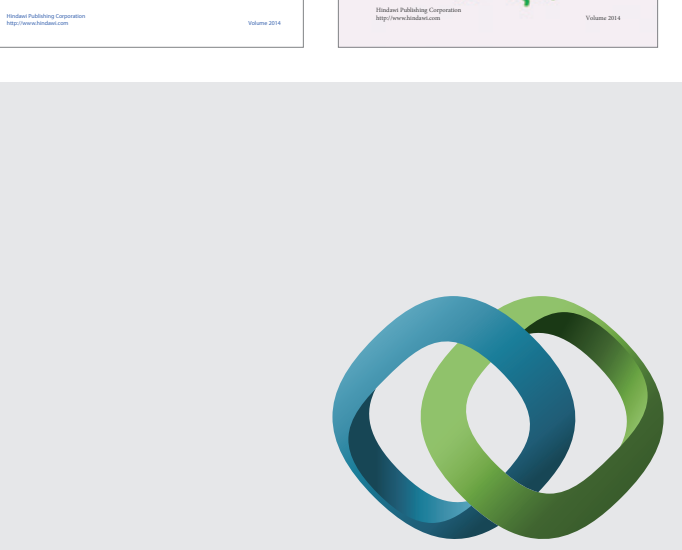

\section{Hindawi}

Submit your manuscripts at

http://www.hindawi.com
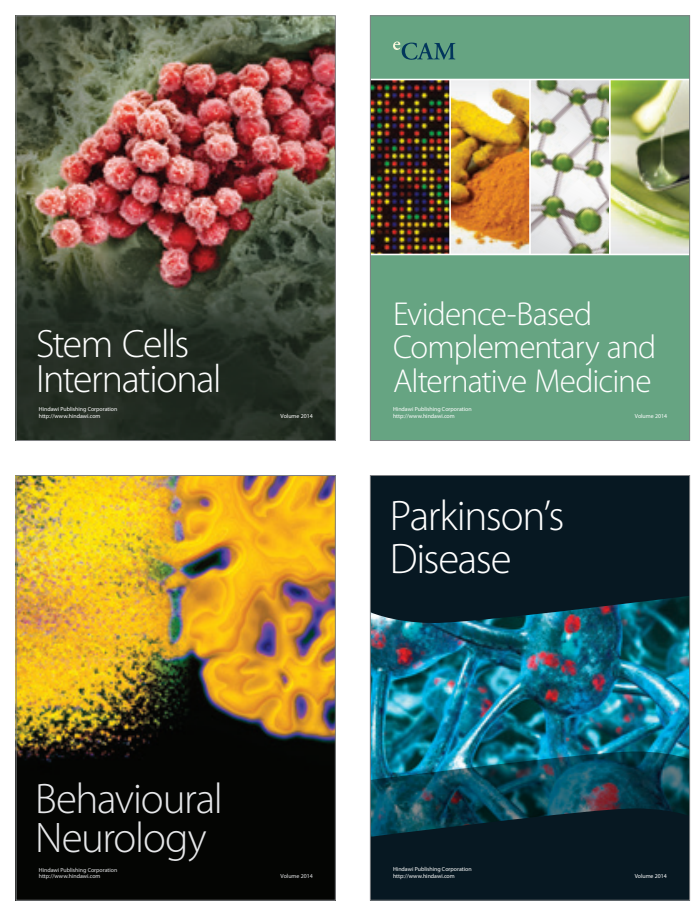

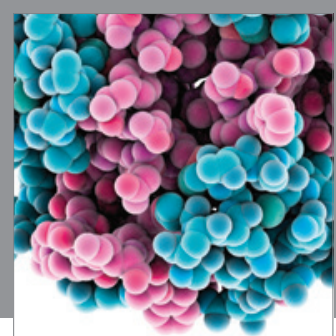

Journal of
Diabetes Research

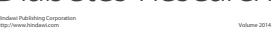

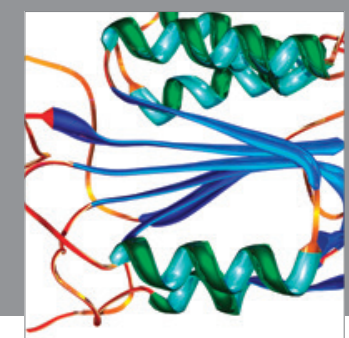

Disease Markers
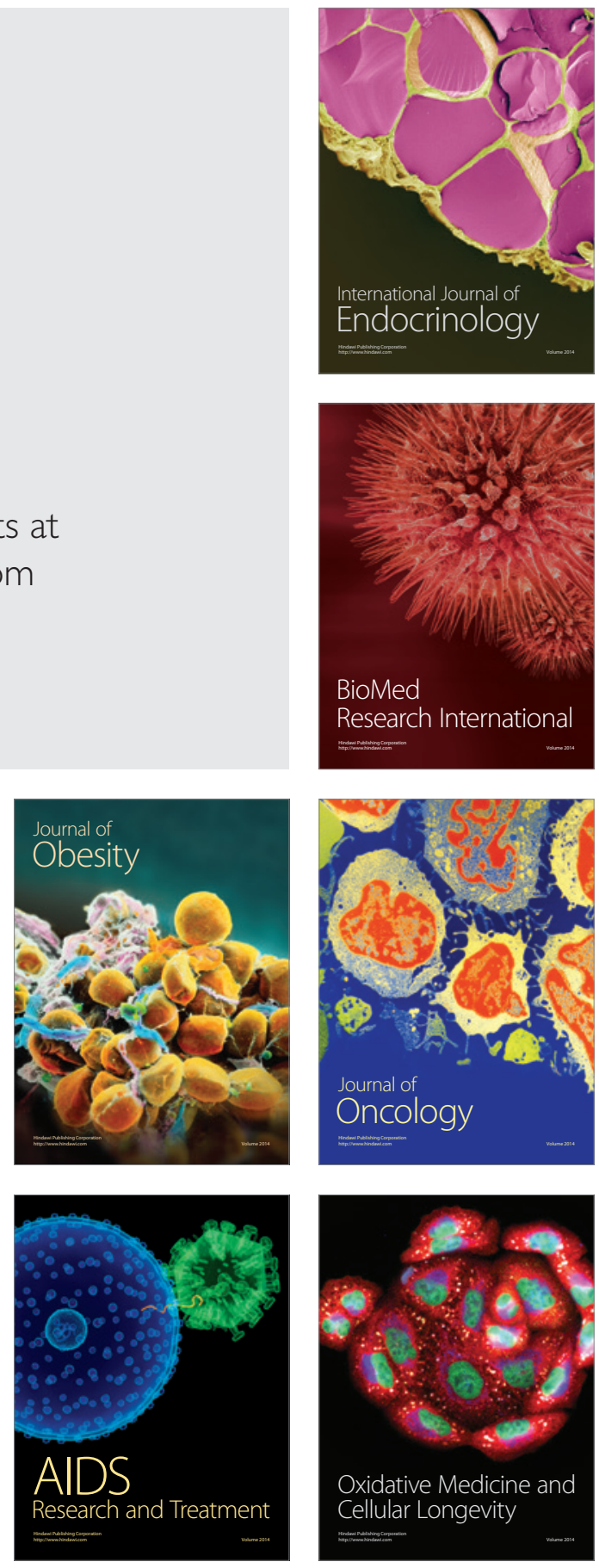